\title{
Thermal Calculations for the Design, Construction, Operation, and Evaluation of the Spent Fuel Test-Climax, Nevada Test Site
}

\author{
D. N. Montan \\ W. C. Patrick
}

Manuscript date: September 30, 1981

\section{, HOTIGE}

PORTIONS OF THIS REPORT ARE ILLEGIBLE. It has h-an renroduced from the best available

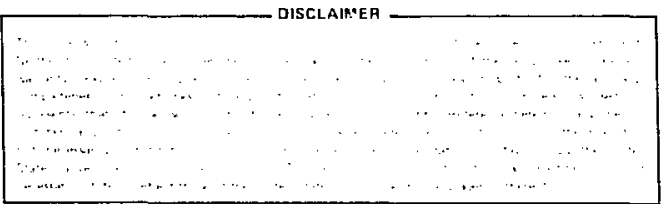
cony ' $\mathrm{n}$ permit the broadest possible availahi'"y.

\section{LAWRENCE LIVERMORE LABORATORY}

University of California - Livermore, California 94550 
Abstract

1. Introduction

1.1. Test Rationale and objectives

1.2. Report Objectives

2. Test Location and Geology

3. Calculational Techniques

3.1. Analytical Solutions

3.2. Numerical Solutions

3.2.1. Radiation

3.2.2. Convection

3.2.3. Ventilation

3.2.4. Boundary Conditions

4. Spent Fuel Test Design Calculations

4.1. Fuel Rod Cladâing Temperature . . . . . . . . . . . . 13

4.2. Model Repository • . . . . . . • . . . • . • • . 14

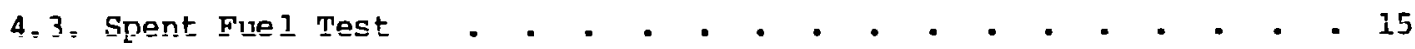

4.3.1. Comparison of SFT-C Design and Repository Model . • . 17

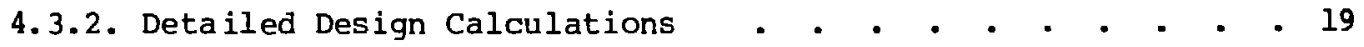

4.3.3. Effects of Radiation, Convection, and Ventilation . - . 21

4.4. Instrumentation Selection and Utilization . - • • • • • • • 23

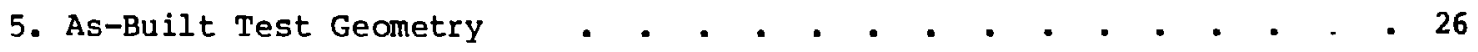

5.1. Spent Fuel Test Layout . . • • • • • • • • • • • . 26

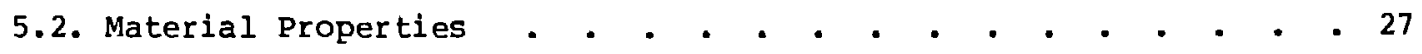

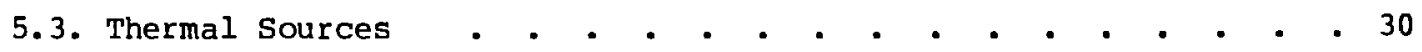

5.4. Ventilation System . • • • • • • • • • • • • • • 33

6. Results of As-Built Calculations . . . . . . . . . • • . . 34

6.1. Fuel-Rod-Cladding Temperature . • • • • • • . . • • . 34

6.2. Air and Fixture Temperatures . . • . • • • . • • • • . 36

6.3. Near-Field Temperature Histories . • . . . • . • • • . 37

6.4. Temperature .rofiles . • • • • • • • • • • . • • • 37

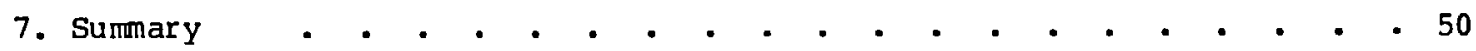

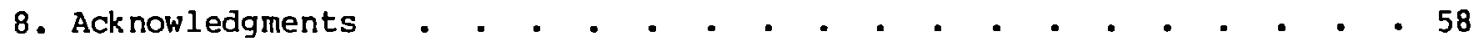

9. References • 
THERMAL CALCULATIONS FOR THE DESIGN, CONSTRUCTION, OPERATION, AND EVALUATION OF THE SPENT FUEL TEST--CLIMAX, NEVADA TEST SITE

\section{ABSTRACT}

The Spent Fuel Test--Climax (SFT-C) is a tesi of retrievable deep geologic storage of commercially generated spent nuclear reactor fuel in granitic rock. Eleven spent fuel assemblies, together with six electrical simulators and 20 guard heaters, are emplaced $420 \mathrm{~m}$ below the surface in the climax granite at the U.S. Department of Energy Nevada Test Site. On June 2, 1978 LLNL secured funding for the SFT-C, and completed spent fuel emplacement May 28, 1980.

This report documents a series of thermal calculations that were performed in support of the SFT-C. Early calculations employed analytical solutions to address such design and construction issues as drift layout and emplacement hole spacings. Operational aspects of the test required more detailed numerical solutions dealing with ventilation and guard-heater power levels. The final set of calculations presented here provides temperature histories throughout the test facility for evaluation of the response of the SFT-C and for comparison of calculations with acquired data. This final set of calculations employs the as-built test geometry and best-available material properties.

\section{INTRODUCTION}

A test of retrievable dry geologic storage of spent fuel assemblies from an operating commercial nuclear reactor is underway in a granitic intrusive at the Nevada Test Site of the U.S. Department of Energy (DOE). This project, generally referred to as the spent Fuel Test--Climax (SFT-C), is part of the DOE Nevada Nuclear Waste Storage Investigations, which are managed by the Nevada Operations office of the DOE. The Lawrence Livermore National Laboratory (LLNL) is responsible for the technical direction of the test. ${ }^{1}$ This generic test is located $420 \mathrm{~m}$ below the surface in the climax granite stock. Eleven canisters containing spent fuel assemblies approximately 2.5 years out of reactor core have been emplaced in the floor of a storage drift along with six electrical simulator canisters. The effects of the spent fuel will be compared with those of electrical simulators. Two adjacent parallel drifts contain electrical heaters that are being operated to simulate, within the test array, the thermal field of a large repository. 
During the test, thermomechanical data are being obtained which may ultimately be useful in designing a spent fuel repository in granite or other crystalline rock. Calculational results will be compared with data to assess the adequacy of the calculational tools.

Calculations have been performed using different initial spent fuel power levels as these levels became better known. Conceptual design calculations assumed $2.0-\mathrm{kW}$ initial power level at 2.5 years out of core. ${ }^{1} \mathrm{~A}$ second set of calculations used a somewhat improved estimate of about $1.8 \mathrm{~kW}$, which was based on additional information on fuel burnup. ${ }^{2}$ Calorimetry and revised ORIGEN decay heat calculations resulted in a power level of $1.5 \mathrm{~kW}$, which was used in the as-built thermal calculations.

\subsection{Test Rationale and Objectives}

It is not widely accepted that the packaging, handling, and storage of wastes from the nuclear industry are straightforward engineering problems. The availability of the required technology is being shown at the SFT-C in accordance with the general objective of the test to demonstrate the safe and reliable short-term storage and retrieval of spent nuclear reactor fuel at a plausible repository depth in a typical granitic rock.

In addition to this general objective, the test has two main technical objectives. These are, first, to simulate the effect of thousands of canisters of nuclear waste emplaced in a geologic media using only a small number of spent fuel assemblies and electrical heaters and, second, to evaluate any differences between the effect on the test environment of an actual radioactive waste source and an electrical simulator. The first technical objective will be met in a $15-\mathrm{m} \times 15-\mathrm{m}$ repositor $y$-model cell, which is centrally located in the test array (Fig. 1). The second technical objective will be met in the region outside the model cell where spent fuel canisters and thermally identical electrical resistance heaters are emplaced in alternating positions. This region hosts the radiation effects experiment (Fig. 1).

Several secondary technical objectives are also being pursued. These include:

- To compare the magnitude of displacement and stress effects from mining alone with the magnitude of thermally induced displacement and stress that occur after the spert Euel is introduced. 


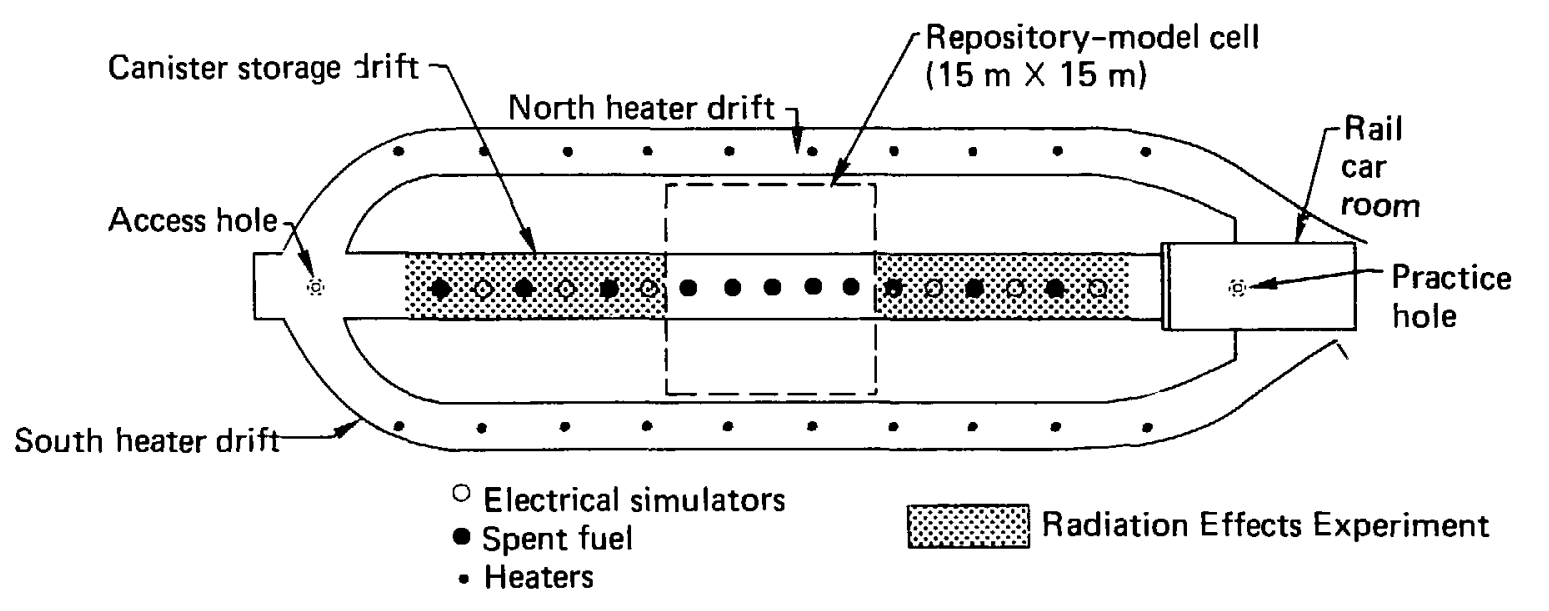

Figure 1. Plan view of the Spent Fuel Test--Climax.
- To document quantitatively the amcunt of heat (about one-third of the total, according to calculations) removed by ventilation.
- To compare the response of rock with various fracture densities to thermal load.

\subsection{Report Objectives}

The principal abjective of this report is to document and present the thermal analyses used during all phases of the SFT-C, from test conception to the present. Many of the design, construction, and operations aspects of these calculations have been reported, in brief, previously. ${ }^{1-3}$ A complete discussion of the calculational techniques, assumptions, properties, and boundary conditions is presented here. The final set of calculations included in this report is based on the as-built geometry of the SFr-C and employs the current best-available data on power inputs, ventilation rates, and thermal properties of materials present.

The initial pretest calculations were completed prior to fuel emplacement ${ }^{2}$ but the power level used in those calculations was $1.8 \mathrm{~kW}$ at 2.5 years out of core. Several weeks before emplacement began, calorimetry data were obtained that indicated that a value of $1.5 \mathrm{~kW}$ was more appropriate. This more accurate value was used in the as-built calculations. In addition, actual rather than design ventilation rates were modeled in the final calculations.

Jespite the fact that this report is published after the test has been in operation over a year, all calculations presented here were performed without 
adjustments for measured temperatures. Adjustments may be made to thermal prc serties and modeling details at a later date if acquired data justify such action.

The results of these calculations, together with required input, are in archival storage in the project Quality Assurance files.

\section{TEST LOCATION AND GEOLOGY}

The SFT-C is located in the northeast quarter of the Nevada Test Site, which is about $100 \mathrm{~km}$ northwest of Las Vegas, Nevada. The test is named for the Climax granitic stock in which it is located (Fig. 2). The Climax stock

LEGEN D

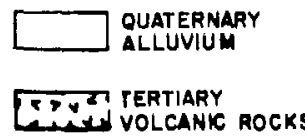

MESOZOIC GRANITIC ROCKS

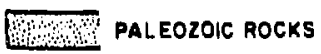

LUL CALDERA

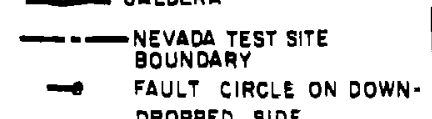
DROPPED SIDE SCALE
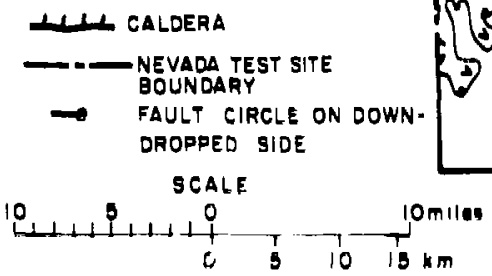
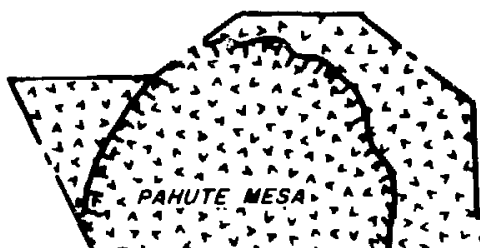

(2)
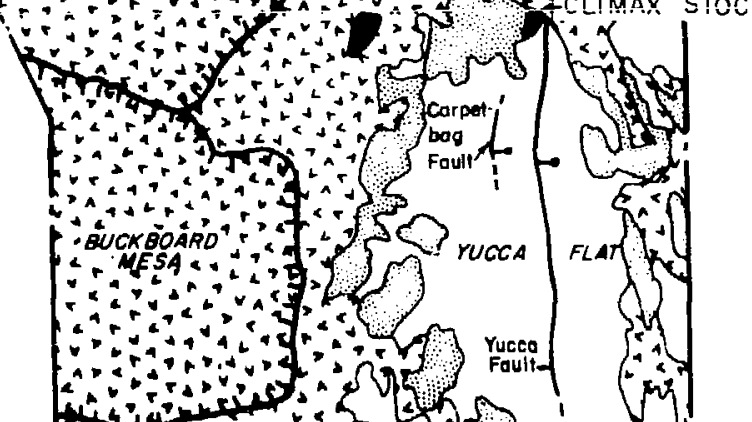

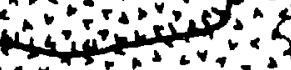

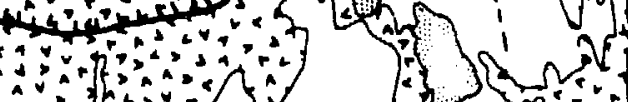

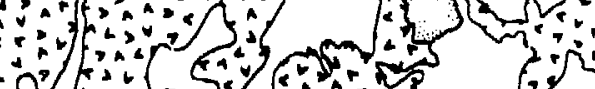
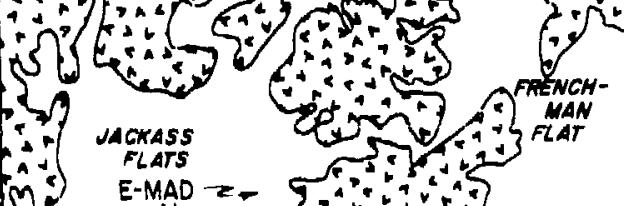

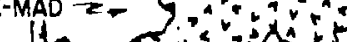
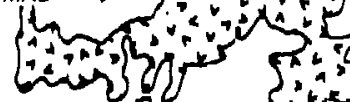

$S_{1}^{1}$
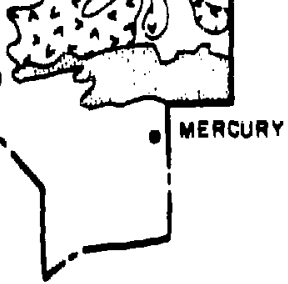

Figure 2. Location of Spent Fuel Test--Climax site (from Ref. 4). 
Table 1. Comparison of rock properties.

\begin{tabular}{lcc}
\hline Property & $\begin{array}{c}\text { Climax Stock } \\
\text { quartz monzonite }\end{array}$ & $\begin{array}{c}\text { Typical granite/ } \\
\text { granodiorite }\end{array}$ \\
\hline $\begin{array}{l}\text { Dry density, Mg/m } \\
\text { Porosity, } 8\end{array}$ & $2.6-2.66$ & $2.53-2.67$ \\
Compressive strength, MPa & $0.7-1.1$ & $0.44-3.98$ \\
Young's Modulus, GPa & 210 & $180-260$ \\
Poisson's Ratio & $61.4-69.7$ & $30-69$ \\
Thermal conductivity, W/m-K & $0.21-0.22$ & $0.1-0.2$ \\
\hline
\end{tabular}

outcrops over an area of about $4 \mathrm{~km}^{2}$ on the surface and expands conically with depth. The SFT-C is located $420 \mathrm{~m}$ below surface where a shaft was sunk for nuclear weapons effects testing in the early 1960 's. 1

The Climax stock consists of two intrusive units: a quartz monzonite and a qranodiorite. The SFT-C is contained completely within the quartz monzonite unit. Laboratory properties of the rock are typical of other granitic rocks (Table 1). In situ testing has refined several of the values given in Table 1 . Current best estimates of in situ modulus and Poisson's ratio are $26 \mathrm{GPa}$ and 0.246 , respectively. ${ }^{10}$ Heater test results indicate an in situ thermal conductivity of $3.1 \mathrm{~W} / \mathrm{m}-\mathrm{K}$ and a thermal diffusivity of $1.26 \mathrm{~mm}^{2} / \mathrm{s} .11$

Geologic investigations at the test site defined three principal joint sets. 12 These are oriented $\mathrm{N} 32^{\circ} \mathrm{W}-22^{\circ} \mathrm{NE}$, N69W-near vertical, and N35Enear vertical. Although the material filling these joints may be quite different from the host rock, they are not believed to perturb the thermal field because of their generally limited thickness. The joints are not, therefore, modeled explicitly either as individuals or as sets in the thermal calculations.

\section{CALCULATIONAL TECHNIQUES}

The selection of calculational techniques was tailored to meet our needs during a particular phase of the project. Thus, simple analytical techniques were used during conceptual design. Increasingly more sophisticated models, 
and associated codes, were employed as more detailed and more precise calculations became necessary for final design, operation, and comparison of calculations with data.

\subsection{Analytical Solutions}

In the early phases of the thermal calculations a simplified model was used to describe the repository. The granite was considered to be homogeneous, isotropic, and of infinite extent. The model repository, or the spent fuel test, was modeled as an array of parallel finite line sources whose length was that of the spent fuel assembly $(\sim 4 \mathrm{~m})$.

This model, of course, ignores the existence of the mined drifts used to emplace the spent fuel and the drill holes in which they are stored. The neglect of the drifts was considered to be conservative in the sense that temperatures calculated would be higher than the "real world" since the openings would be better conductors than the rock they replaced and any ventilation would remove heat from the system. The use of line sources rather than cylinder sources affects oniy eariy transients (which wili be shown beiow to be on the order of a few days).

The calculational techniques used in this phase were also quite simple, namely the superposition in space and time of the continuous point source solution of the diffusion equation:

$\Delta T=\frac{Q}{4 \pi k d} \operatorname{erfc} \sqrt{\frac{d^{2}}{4 k t}}$,

where

$$
\begin{array}{ll}
\Delta \mathrm{T} & =\text { temperature rise }(\mathrm{K}) \\
\mathrm{Q} & =\text { source strength }(\mathrm{W}) \\
\mathrm{d} & =\text { distance from source }(\mathrm{m}) \\
\mathrm{k} & =\text { thermal conductivity }(\mathrm{W} / \mathrm{m}-\mathrm{K}) \\
\mathrm{K} & =\text { thermal diffusivity }\left(\mathrm{m}^{2} / \mathrm{s}\right) \\
\mathrm{t} & =\text { time }(\mathrm{s}) \\
\text { erfc } & =\text { complementary error function. }
\end{array}
$$


Using this superposition technique, one can obtain the temperature-time history at any point to any desired accuracy by using a sufficiently large number of point source solutions. Preliminary calculations (involving a few sources and a few points in time) were done with a table of the error function and a calculator. A variety of small computer programs was later developed which did the desired "bookkeeping," simple arithmetic, and called an error function subroutine. With a modern high-speed computer that can calculate an error function in 10-20 $\mu \mathrm{s}$ this becomes a rather powerful tool with which the effects of various parameters can be studied quickly and easily. Questions concerning the number of points required to represent a line or the minimum subdivision in time were easily answered by numerical experimentation.

As a result of some such calculations, we have found that, for the purpose of the work being reported here, the number of points required to represent a line could be estimated by

$N=a\left(\frac{L}{k}\right)+b$,

where $\mathrm{L}$ is the source length, $\mathrm{R}$ is the perpendicular distance from the line to the point at which the temperature is being calculated. Values of "a" between 1 and 2 and "b" between 2 and 5 kept errors below a few percent. Likewise 10 to 20 intervals in time were generally quite adequate for these early phase calculations and kept errors to within a few percent.

\subsection{Numerical Solutions}

Several of the simplifying assumptions that were used in the early phase analytical techniques were known to be false in the actual SFT-C. The presence of ventilated underground openings required treatment of radiative and convective heat transfer as well as heat removal by ventilation. The three-drift array required inclusion of numerous regions possessing different thermal properties. In order to perform more sophisticated calculations, it became necessary to select a computer program capable of generating numerical solutions for complex geometries.

A wide variety of computer programs is available for solving problems involving the diffusion equation. ${ }^{13}$ Any of the better ones should have the capacity for addressing the SFT-C geometry. We chose to use the finitedifference computer program TRUMP ${ }^{14}$ for several reasons: 
- It is widely accepted and considered one of the best.

- It has more than enough flexibility to implement our current model.

- It is resident at LLNL and is thus readily available to us on all of our major computers.

- It has been around long enough (over 15 years) to be considered mature (all the known "bugs" have been corrected).

- The person utilizing the code for these calculations is thoroughiy Eamiliar with it.

One major drawback to the use of TRUMP (or presumably any other highly flexible diffusion-equation solver), particularly to the casual user, is the great amount of detail reguired as input. For our model with over 2500 zones, the input instructions could well consist of several thousand lines. Any serious user quickly gets tired of punching cards and soon acquires or creates a preprocessor designed to create input for the type of geometry he desires. We have a small program (GRUMP) which contains a variety of subroutines to create TRUMP input for several different types of problems. In general, a small set of instrictions to GRUMP will generate over $90 \%$ of the input for TRUMP. The remaining 108 that has to be put together by hand is generally tedious but tolerable.

3.2.1. Radiation. Thermal radiation was modeled by straightforward application of the radiation transport relations for gray enclosures

$q_{12}=A_{1} \underline{F}_{12} \sigma\left(T_{1}^{4}-T_{2}^{4}\right)$

where

$$
\begin{aligned}
& \mathrm{q}_{12}=\text { flux from surface } 1 \text { to surface } 2 \\
& \mathrm{~A}_{1}=\text { area of surface } 1 \\
& \underline{F}_{12}=\text { radiative form factor } \\
& \sigma=\text { stefan-Boltzmann constant } \\
& \mathrm{T}=\text { absolute temperature. }
\end{aligned}
$$

Since the emittance of the rock surface is near unity $(0.8$ was used in most calculations), the simplifying approximation was used:

$\underline{F}_{12}=E F_{12}$ 
where

$$
\begin{aligned}
& E=\text { emittance } \\
& F_{12}=\text { geometric view factor } .
\end{aligned}
$$

One important consideration (often overlooked) is that in models having plane(s) of symmetry (such as occur in our model) the adiaba' 'c boundary :ondition at such planes is equivalent to a mirror. Thus the "half" main drift in our model with 16 radiating surfaces, 5 each on the roof and floor and 6 on the wall, has 185 radiative connections.

3.2.2. Convection. Heat transfer from the drift surfaces to the air in the drift may be expressed by

$\mathrm{q}=\mathrm{AH} \Delta \mathrm{T}$,

where $\mathrm{H}$ is the convection coefficient (typical units $\mathrm{w} / \mathrm{m}^{2}-\mathrm{K}$ ). For the convection coefficient we have used a standard empirical correlation for natural convection in the turbulent regime relating the Nusselt number (iv ${ }_{\text {Nu }}$ ) to the Rayleigh number $\left(\mathrm{N}_{\mathrm{Ra}}\right)^{2}$ :

$\mathrm{N}_{\mathrm{Nu}}=0.13\left(\mathrm{~N}_{\mathrm{Ra}}\right)^{1 / 3}$

where the Rayleigh number is the product of the Grashof number and the Prandt1 number:

$\mathrm{N}_{\mathrm{Ra}}=\mathrm{N}_{\mathrm{Gr}} \cdot \mathrm{N}_{\mathrm{Pr}}$

The above correlation leads to an expression for the convection coefficient of

$\mathrm{H}=\mathrm{a}(\Delta \mathrm{T})^{1 / 3}$

where the (dimensional) factor " $a$ " is a function of the physical properties of air and the absolute temperature. At $300 \mathrm{~K}$ and an elevation of $1100 \mathrm{~m}$, corresponding to the SFT-C, it has the value

$a=1.5 \mathrm{~W} / \mathrm{m}^{2} \mathrm{k}^{4 / 3}$ 
Forced convection due to the flow of ventilation air should also be considered if the inertial forces du, to the forced air flow are comparable to the buoyancy forces from heating. The ratio of these forces is given by:

$\frac{\text { Buoyancy }}{\text { Inertial }}=\frac{\mathrm{N}_{\mathrm{Gr}}}{\mathrm{N}_{\mathrm{Re}}^{2}}$,

where $\mathrm{N}_{\mathrm{Re}}$ is the Reynolds number. For our model $\mathrm{N}_{\mathrm{Gr}} \sim 10^{10}$ to $10^{11}$, and for our planned ventilation rate $\left(1 \mathrm{~m}^{3} / \mathrm{s}\right.$ in the main drift and $1 / 2 \mathrm{~m}^{3} / \mathrm{s}$ in each of the heater drifts) $\mathbb{N}_{\mathrm{Re}} \sim 10^{4}$. Thus natural convection clearly dominates.

3.2.3. Ventilation. The heat removed from a repository or the spent Fuel Test by ventilation can amount to a significant fraction of the heat produced. Furthermore, the temperature rise of the air as it flows through the drift is nearly a linear function of the flowrate. Thus a careful approach to the calculation of the thermal effects of ventilation seems prudent.

One approach to the ventilation problem (which we have seen used) is to hold the air (or some external boundary representing it) at the ambient air/rock temperature and then, using convection coefficients, perhaps as described in the previous section, proceed with the calculation. This ventilation model, while easily incorporated into the unit-cell model (Section 4.3.2), has several serious drawbacks. In the Spent Fuel Test, a fixed amount of air will enter one end of a drift and be removed at the other, picking up heat and rising in tempernture as it passes through. A fixed air temperature model woula overestimate the heat removed, underestimate the rock temperatures (particularly the drift surfaces) and give no estimate of what the actual air temperature would be. On the other hand, physical approximation of the fixed air temperature mojel would require inordinately high ventilation rates.

In order to retain the unit-cell model and still do realistic ventilation effects calculations, we have adopted a "partial-flow" model in which the unitcell receives only a fraction of the total flow, but that partial-flow enters the cell at ambient and leaves at the average air temperature of the cell. The heat removal may then be expressed as:

$q=\rho c \dot{V} \cdot \Delta x T$, 
where

$$
\begin{aligned}
& \rho=\text { air density }\left(\mathrm{kg} / \mathrm{m}^{3}\right) \\
& \mathbf{C}=\text { specific heat at constant pressure }(\mathrm{J} / \mathrm{kg}-\mathrm{K}) \\
& \dot{\mathrm{V}}^{\prime}=\text { flowrate per unit length of } \mathrm{drift}\left(\mathrm{m}^{2} / \mathrm{s}\right) \\
& \Delta \mathrm{x}=\text { length of calculational cell }(\mathrm{m}) \\
& \mathrm{T}=\text { temperature rise above ambient }(\mathrm{K}) .
\end{aligned}
$$

The question then arises as to what is the correct numerical 'value of $\dot{V}^{\prime}$. If physical implementation of ventilation was such that the air within the drift was well-mixed so that the air temperature at any location along the drift was the same at a given time, the numerical value of $\dot{V}^{\prime}$ would simply be the tocai filow divided by the active length of the array (about $50 \mathrm{~m}$ in this aase). On the other hana, if air moves through the drift with no mixing, we have a case of slug flow in which air enters the drift at ambient and gradually becomes hotter as it progresses from cell to cell down the drift to the exhaust point. A useful approach for modeling these flow conditions is to visualize each cell as thermally isolated from every other cell with its own separate inlet and exhaust ports. For the case of well-mixed flow, we once again apportion flow uniformly to each cell at ambient and remove its portion at the average air temperature of the cell (all of which temperatures are the same). For the case of slug flow, we apportion more of the flow to the cell nearest the inlet and gradually less to each cell farther from the inlet. Thus, in the model, a partial flow enters each cell at ambient and leaves at the average temperature of each cell (all of which temperatures are different: increasing with increasing distance from the inlet). Several different values of $\dot{V}^{\prime}$ must be used in a single unit-cell model calculation since each value is applicahle to a different location in the drift.

In the situation that we actually wish to model, a constant air flow, $\dot{v}_{0}$ $\left(\mathrm{m}^{3} / \mathrm{s}\right)$, passes through the drift and at some point while traveling a distance $\Delta \mathbf{x}$ the temperature increases by an amount $\Delta \mathrm{T}$. The heat removal is then:

$q=\rho c \dot{V}_{0} \Delta \mathrm{T}$

By equating this equation and the previous one and passing to the limit as $\Delta x$ becomes infinitesimal we obtain:

$$
\frac{\mathrm{dT}}{\mathrm{dx}}=\frac{\dot{\mathrm{V}}^{\prime} \mathrm{T}}{\dot{\mathrm{v}}_{0}}
$$


Thus, by using different values of $\dot{V}^{\prime}$ in the (complete) model and calculating the resulting air temperatures at a time or times of interest, a functional relationship between $\dot{V}^{\prime}$ and $T$ may be obtained. The above differential equation may then be integrated to give the desired result: air temperature rise as a function of distance along the drift. In practice we find that the product $\dot{V}^{\prime} T$ is adequately approximated as a linear function of $T$

$\dot{V}^{\prime} T=a_{0}+a_{1} T$

where $a_{0}$ and $a_{1}$ are determined from the results of the numerical calculations. In this case the differential equation may be integrated to give

$T=-\frac{a_{0}}{a_{1}}\left[1-\exp \frac{a_{1} x}{\dot{v}_{0}}\right]$.

3.2.4. Boundary Conditions. The conditions imposed at the boundaries of a computational mesh can have a significant effect on calculated results. One of two boundary conditions is typically employed in thermal calculations. First, boundaries may be treated as adiabatic; making them, in effect thermal reflectors. This condition will produce the highest possible temperatures at the boundary, assuming 1, aat is being added to the system. Second, boundaries may be fixed at a constant temperature; making them heat sinks. This condition will produce the lowest possible temperatures at the boundary, assuming once again that heat is being added to the system.

Since we know that neither condition is quite true in the actual repository, we perform a simple test to assure ourselves that the thermal boundary is far enough removed from the heat sources that it will not greatly perturb the results. The desired calculation is performed with each boundary condition. If the calculations show insignificant differences in temperatures within the region and for the times of interest for the two boundary conditions, the mesh is large enough.

Tile time constant also provides a straightforward answer to the question of mesh size. Experimentalists who are unfamiliar with thermal analyses may find the previous calculation for two boundary conditions more satisfying. The time constant is calculated using the distance from the thermal source to the nearest boundary, L, and the thermal diffusivity, $K$. 
$t_{c}=L^{2} / K$.

For a typical mesh used in calculations presented here:

$t_{c}=\frac{(70 \mathrm{~m})^{2}}{1.26 \times 10^{-6} \mathrm{~m}^{2} / \mathrm{s}} \simeq 125$ years.

Since the test is of 3- to 5-year duration, we clearly are utilizing a large enough mesh.

\section{SPENT FUEL TEST DESIGN CALCULATIONS}

It was clear from the initiation of the SFT-C that the principal objective of "demonstration of safe and reliable storage" carried with it the implication of demonstration within a realistic environment. The design calculations had three aims, the first of which was establishment of a facility geometry which met the principal test objective. Second, these early calculations addressed a safety and handling problem of fuel cladding temperatuie. Third, they supported preconceived selection and placement of temperature transducers.

These conceptual design calculations all assumed $2.0 \mathrm{~kW}$ at 2.5 years out of core. Subsequent calculations have used lower thermal output and were keyed to the average date of actual emplacement. It is important for the reader to keep in mind that the original calculations reproduced in section 4 are illustrative of design considerations and differ from the as-built calculations discussed in Sections 5 and 6 .

\subsection{Fuel Rod Cladding Temperature}

It is important to the success of the test that the spent reactor fuel remain physically intact during handling, storage, and retrieval operations. Current recommendations are that the zircalloy fuel-pin cladding not be subjected to temperatures exceeding $380^{\circ} \mathrm{C} .15$

To calculate the canister skin temperature, we considered radiative transport across the two air gaps, between the rock surface and the liner, and between the liner and the canister surface. * No allowance was made for a

* See canister storage configuration in Fig. 14. 
concrete bond between the rock and the liner or for conductive or convective heat transport. This calculation should be conservative. Emittances of 0.8 for the rock and steel liner and of 0.4 for the stainless steel canister were used.

The calculation of peak cladding temperature used both radiative transport between the 204 fuel pins and canister wall and conduction through the helium fill-gas. These calculations were performed using a relaxation technique for steady state heat transport. Convection was not considered in the interior of the fuel assembly, but it was simulated in the region between the fuel and canister by a 15-mm convective transport film thickness. Emmittances of 0.4 were used for both cladding and canister. The conductivity/temperature ratio used for the helium was $4 \times 10^{-7} \mathrm{~W} / \mathrm{mm}-\mathrm{K}^{2}$.

Using a pin diameter of $10.22 \mathrm{~mm}$ and a pitch-to-dianeter ratio (center-tocenter distance) of 1.4 , one obtains the following results:

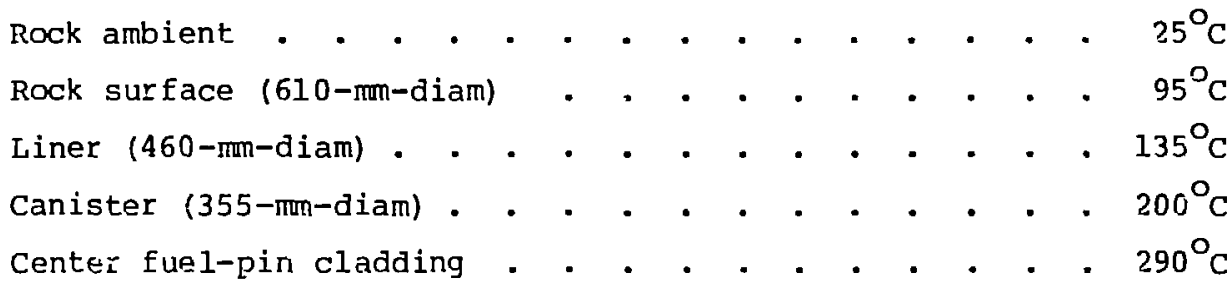

Thus, the fuel-pin cladding is shown to be substantially lower than the recommended peak.

A sensitivity analysis using a range of values for all important parameters was undertaken to determine the worst case cladding temperature. $^{1}$ The combined result of increasing canister power to $2.5 \mathrm{~kW}$, disallowing thermal conductance in the canister backfill gas, and degrading all other thermal properties in the region surrounding the canister produced a peak cladding temperature of $383^{\circ} \mathrm{C}$, oniy slightly over the recommended limit. It is unlikely that any one of the errors would be as large as was assumed here, much less that all would occur at once. Thus, we judged that the integrity of the cladding would not be jeopardized in the test.

\subsection{Model Repository}

The model repository is simple in design. It consists of a large number of long parallel drifts with spent fuel canisters placed in vertical holes drilled along the center lines of the drifts. This model is not intended to be a recommended or optimum design, but rather a conceptually simple model 
that is not greatly at odds with what might be built in the future. Moreover, simulation of the model in the spent Fuel Test is not overly complicated.

The dimensions used in this model. are $15 \mathrm{~m}$ center-to-center for the drifts with the waste canisters emplaced on $3-\mathrm{m}$ centers along the drifts. The rationale for the $15-\mathrm{m}$ drift spacing was an extraction ratio of $33 \%$ using a projected drift width of $5 \mathrm{~m}$. The rationale for the $3-\mathrm{m}$ storage hole spacing along the drifts was to give enough room for ease of operations. Because the storage holes in the Spent Fuel Test are $0.61 \mathrm{~m}$ in diameter, there is only $2.39 \mathrm{~m}$ of rock between the holes.

As a matter of passing interest, this model, loaded with spent fuel canisters at a power level of $2 \mathrm{kw} / \mathrm{canister}$ would have an initial areal loading density of $190 \mathrm{~kW} /$ acre; a value used in preconceptual design studies for a granite repository. 16

Thermal calculations, using the analytical technique described previously, have been made for the center of such a repository. The parameters used in these calculations were:

$$
\begin{aligned}
& \mathrm{k}=3.0 \mathrm{~W} / \mathrm{m}-\mathrm{K} \\
& \mathrm{K}=1.25 \mathrm{~mm}^{2} / \mathrm{s} \\
& \mathrm{Q}=2 \mathrm{~kW} \text { at } 2.5 \text { years out of reactor core } \\
& \mathrm{L}=3.66 \mathrm{~m} .
\end{aligned}
$$

Some results of these calculations for the hottest (rock) point in the repository (the rock surface at the fuel assembly midpoint in the center hole of the repository) are shown in Fig. 3. The three curves are for spent fuel that has been out of the reactor core for 2.5, 5, and 10 years, respectively, before emplacement in the rock. The calculations were made with a large enough array $(300 \times 300 \mathrm{~m}$, containing 2000 canisters) that the size of the array was expected to have very little effect on the temperature at 100 years (the time constant, $\mathrm{L}^{2} / K$, for the nearest boundary, $150 \mathrm{~m}$, is 570 years). A check calculation for the 2.5-year-old fuel involving an array four times as large $\left(600 \times 600 \mathrm{~m}, 8000\right.$ canisters, $\mathrm{L}^{2} / \mathrm{K}=2250$ years $)$ showed the error at the center to be 4.5 宫 at 100 years. Thus, the results obtained should be applicable to much larger arrays.

\subsection{Spent Fuel Test}

An examination of the thermal histories fo: the model repository shows that spent fuel stored at its likely age in a real repository (5 to 10 or more 


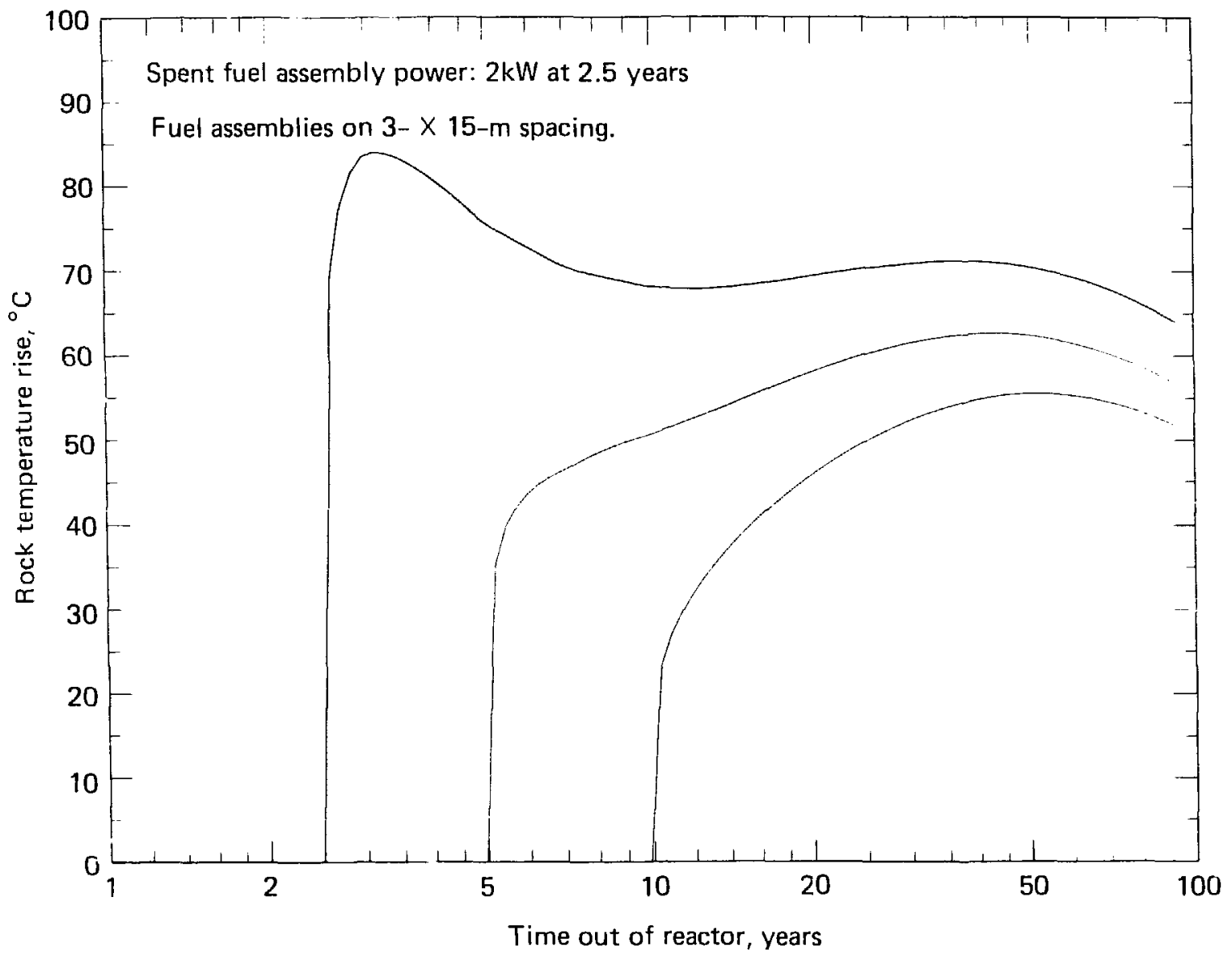

Figure 3. Temperature history of rock surface at fuel assembly midpoint in center hole of hypothetical spent-fuel repository.

years out of reactor core) generates a peak rock temperature rise of $55-60^{\circ} \mathrm{C}$ but only after about 40 years of storage, while fuel stored at an age younger than 3 years generates an early rock temperature peak within the first year that exceeds the later peak (Fig. 3). In the case of 2.5-year-old fuel, the rise is about $85^{\circ} \mathrm{C}$. Thus, the present spent-fuel-storage-test design calls for fuel that has been out of reactor core for about 2.5 years. This will allow the assessment of maximum thermal effects in a few years, as opposed to a few decades, and will also expose the rock to higher temperatures than might be encountered using older fuel in the simple model repository. This information might be useful in the design of more sophisticated repositories with higher fuel assembly loading densities.

After considerable study involving not only thermal effects, but mechanical and mining considerations as well, a spent-fuel-test design evolved. 
The physical layout is shown in Fig. 1. In the storage drift $(4.6 \times 6.1 \mathrm{~m}$ in cross-section) is a linear array of 17 storage holes (on 3-m centers) in which are placed storage canisters, 11 of which contain spent fuel assemblies and 6 of which contain electric heaters whose power level is varied with time to match that of the spent fuel. Thus, for the purposes of most thermal calculations, the 17 canisters are identical. In addition, there are two parailel side drifts $(3.4-\times 3.4-\mathrm{m}$ cross section) each containing a row (10 $\mathrm{m}$ from the storage array) of 10 electric heaters in small holes on 6-m centers. The function of these heaters is (I) to provide a means of maintaining temperatures in the storage canister array as high as would occur in the model repository, and (2) to heat a larger mass of granite than would be affected by the storage array alone.

4.3.1. Comparison of SFT-C Design and Repository Model. Some results of the thermal calculations pertaining to this design are shown in Fig. 4. These

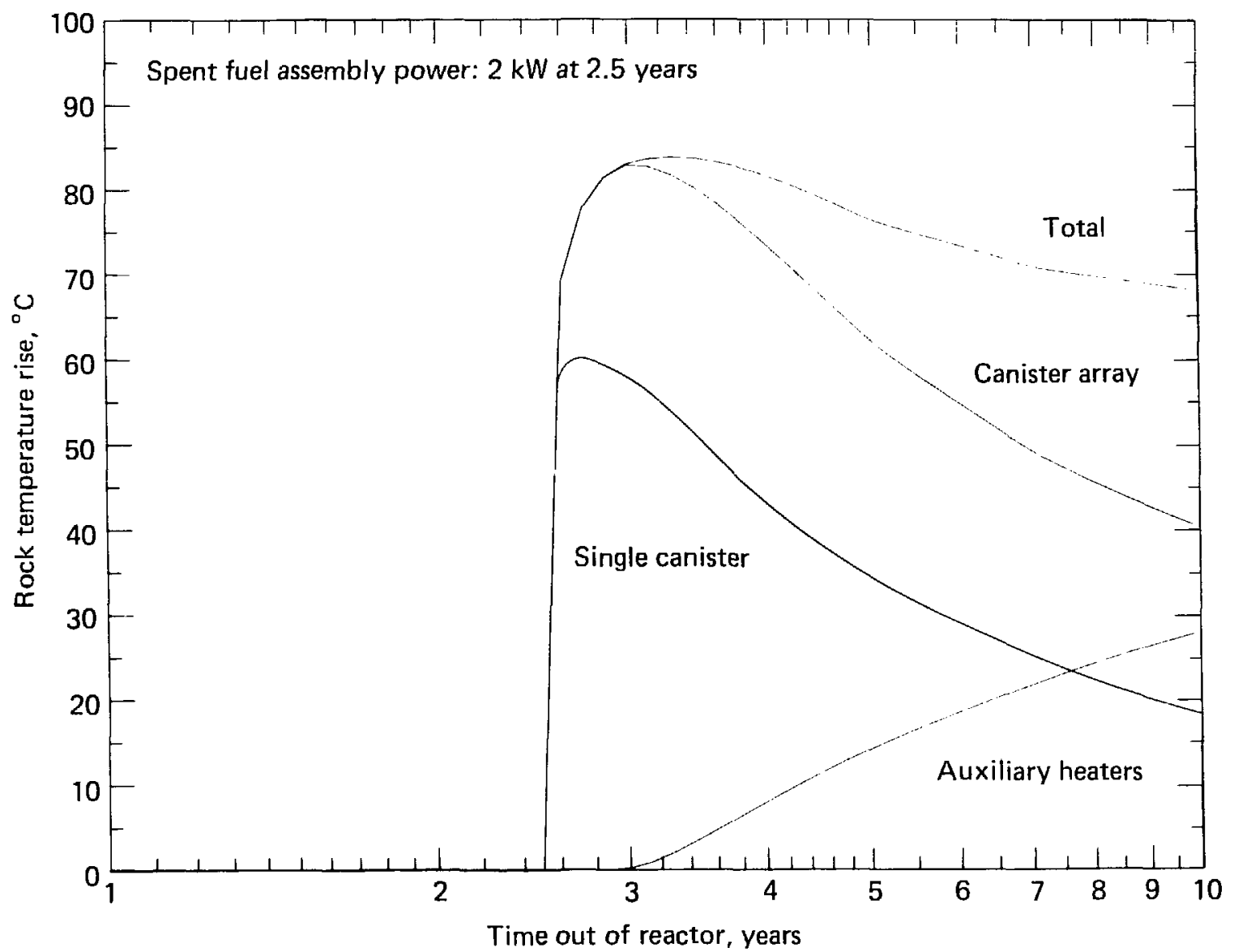

Figure 4. Calculated temperature on the storage-hole wall at canister midplane of 17-canister storage array. 
calculations employed the analytical technique described previously. A single canister gives a peak rock temperature rise of $\sim 60^{\circ} \mathrm{C}$, well below the $85^{\circ} \mathrm{C}$ calculated for the model repository. The 17 canister array peaks within a few degrees of the model repository, but drops to near half the value in 7 years. A number of calculations led to the design of the guard heater power history. When turned on at 0.3 years after the spent fuel is emplaced and maintained at a constant power of $1730 \mathrm{~W}$ each, the heaters produced the contribution shown in the lower curve. When this is added to the canister array curve to give the top curve, the result is a peak rock temperature history chat is remarkably close to that of the model repository. A comparison of peak rock temperature for the model repository and the SFr-C is shown iñ $F i g$. 5. Aaduitionai calculations have shown that the region between the canister row and the heaters experiences a temperature $r$ ise a few degrees higher than the region between rows in the repository design.

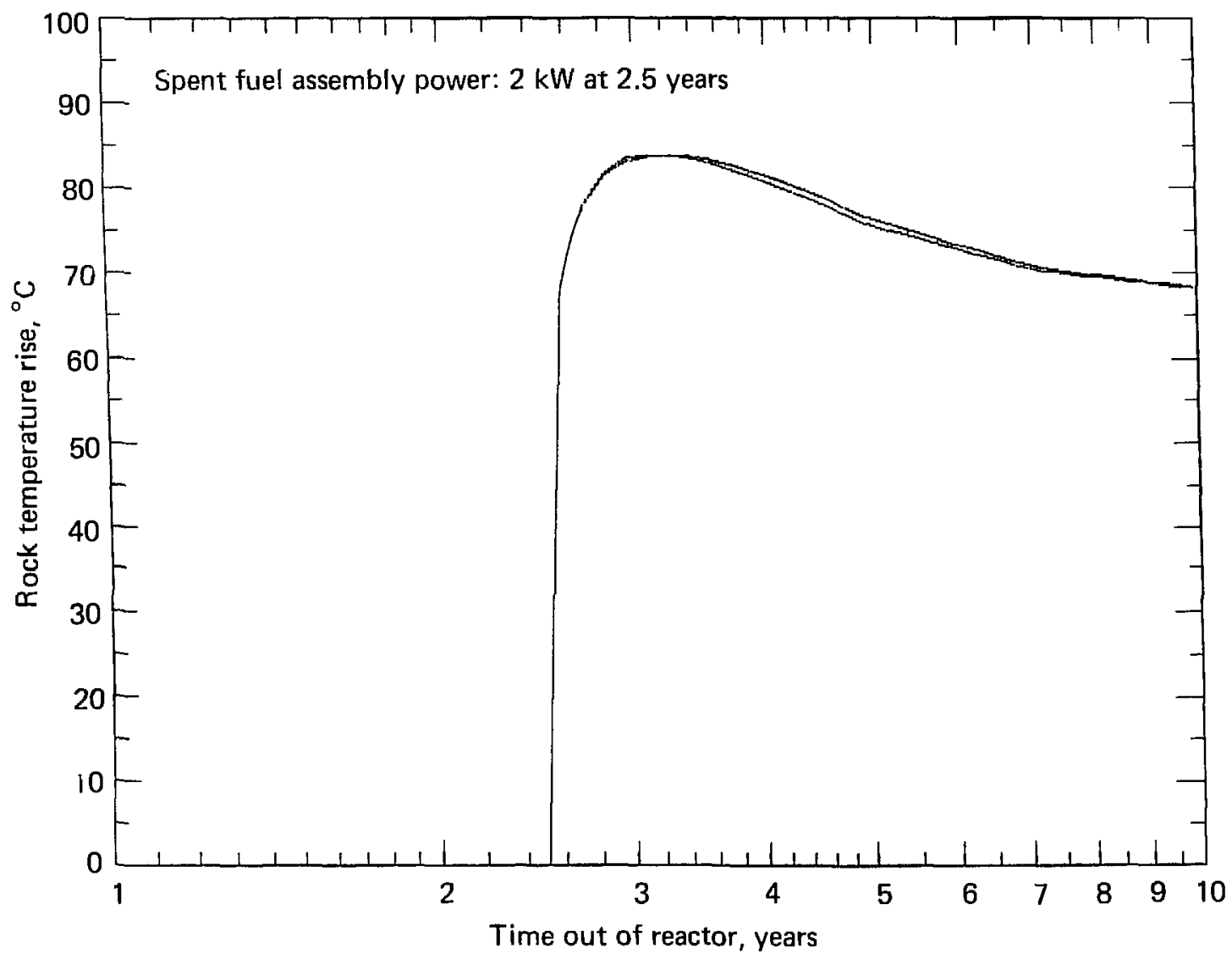

Figure 5. Temperature histories for model repository and SFT-C. 
Thus, the spent-fuel-storage test, as described here, is expected to subject a substantial granitic mass (several thousand cubic metres) to thermal effects that match or exceed those that might be expected in an actual repository in a similar medium.

4.3.2. Detailed Design Calculations. Detailed calculations were required to address ventilation requirements, temperatures of concern in operations and handling, and instrument selection and placement. The TRUMP code was employed to obtain the required numerical solutions to the diffusion equation since the complexity of the problem exceeded the capabilities of analytical solutions.

These detailed calculations were based on a unit cell of the model repository or spent Fuel Test. This cell contains one canister and is bounded by two parallel vertical planes perpendicular to the drifts and spaced half way between canisters. For the model repository calculations, two additional vertical planes of symmetry parallel to and midway between the drifts also bound the unit-cell. The four-fold axis of symmetry at the canister center line provides two more vertical planes of symmetry, thus reducing the required calculations to a region comprising one-fourth of the unit-cell.

The mesh typically used in two-dimensional calculations (Fig. 6) contains three basic regions. The innermost region (Region III) (where most of the temperature change occurs) is $20 \mathrm{~m}$ wide by $40 \mathrm{~m}$ high and is divided into 1600 zones $(0.5 \mathrm{~m}$ by $1 \mathrm{~m})$ to give the desired spatial resolution. The thermal time

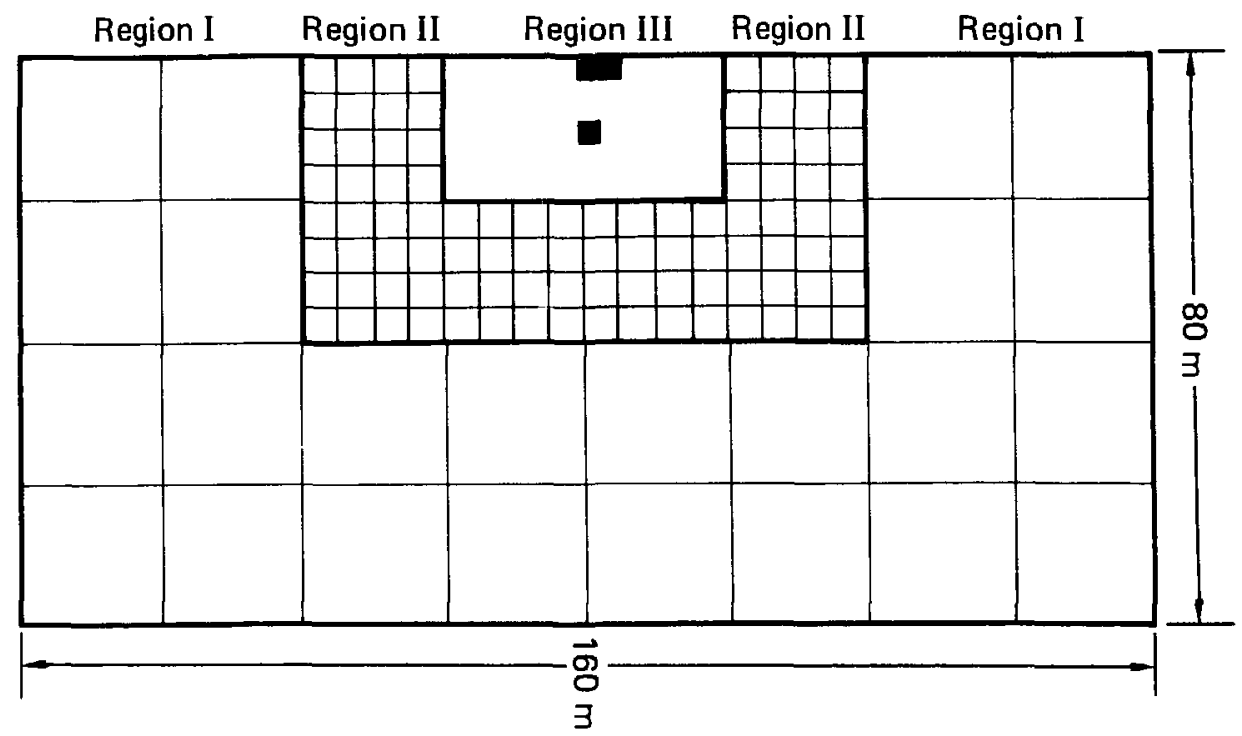

Figure 6. Schematic of mesh used in two-dimensional TRUMP calculations. 
constant based on the smallest source to boundary distance $(10 \mathrm{~m})$ is 2.5 years. To simulate an infinite medium for a longer period of time, two more regions contairing 96 zones $(5 \times 5 \mathrm{~m}$ ) (Region II) and 24 zones $(20 \times 20 \mathrm{~m}$ ) (Region I) were added giving an overall size of $80 \mathrm{~m}$ by $160 \mathrm{~m}$ with a time constant of 120 years. The zone thickness is, of course, half the canister spacing or $1.5 \mathrm{~m}$. In the regions comprising the drifts, the regular zoning was replaced by single zones containing air. In addition, thin (50 mm) zones of rock or concrete as appropriate were placed on the drift surfaces to obtain accurate surface temperatures for radiation and convection calculations. The size of these "tiles" was appropriate to match the larger zones to which they were connected. For the floors and ceilings the tiles were $0.5 \times 0.05 \times 1.5 \mathrm{~m}$ and for the walls $0.05 \times 1 \times 1.5 \mathrm{~m}$.

In a two-dimensional model of the type described above, the discrete cylindrical heat sources are "smeared out" and are actually modeled as a continuous strip source. As a result, the temperatures calculated near the source are too low. However, because of the relative "thinness" of the model (due to the source spacing) the heat flow is truly two-dimensional at distances greater than a few metres from the source. Indeed, for repository calculations with the additional plane of symmetry, heat flow becomes one-dimensional after a distance of 10-15 $\mathrm{m}$ from the source. Thus the two-dimensional model is adequate over most of the region of interest and the t] ird dimension need be included only in a relatively small part of the model.

The three-dimensional part of the model follows the same "nesting" concept used in the two-dinensional part. The zoning becomes progressively finer (in a stepwise fashion) as the source is approached. To start, the 50 zones $(0.5 \times 1 \times 1.5 \mathrm{~m})$ beneath the floor to a depth of $10 \mathrm{~m}$ were replaced with 150 zones $(0.5 \times 1 \times 0.5 \mathrm{~m})$. Next, 54 of these zones comprising a volume $1.5 \times 6 \times 1.5 \mathrm{~m}$ whose midplane coincides with that of the heat source were replaced with 486 zones $(1 / 6 \times 1 \times 1 / 6 \mathrm{~m})$. Finally, 6 corner zones (in a vertical stack) were removed and the surrounding 18 zones reduced in size, leaving the 305-mn radius hole in which to place the canister and steel liner. The liner $(230-\mathrm{mm}$ radius) was represented by 12 zones varying in height from 0.4 to $0.5 \mathrm{~m}$. The canister was represented by 11 zones varying in height from 0.2 to $0.5 \mathrm{~m}$. Seven of these zones represent the active heat source (the fuel assemhly or electrical simulator). Heat transport from the canister to the liner and from the liner to the rock was modeled as radiative and convective with emittances of 0.4 for the stainless steel canister and 0.8 for the liner 
and rock. Zero volume zones were placed on the rock surface in the hole to give correct temperatures for the radiative transport. Additional zones were added as needed to model the concrete plug in the top of the hole, the railroad tracks, and other details. Typical results of these detailed calculations are shown in Fig. 7 where temperatures of several selected locations have been calculated.

4.3.3. Effects of Radiation, Convection, and Ventilation. In some repository calculations that we have seen, the drifts were considered as nonconductors (voids) and thus gave a large temperature difference from floor to ceiling and isotherms that were perpenuicular to the disit surfaces. Such a calculation for SFT-C conditions is shown in Fig. 8 for comparison with subsequent figures. This is quite incorrect. Either thermal radiation (Fig.9) or convection

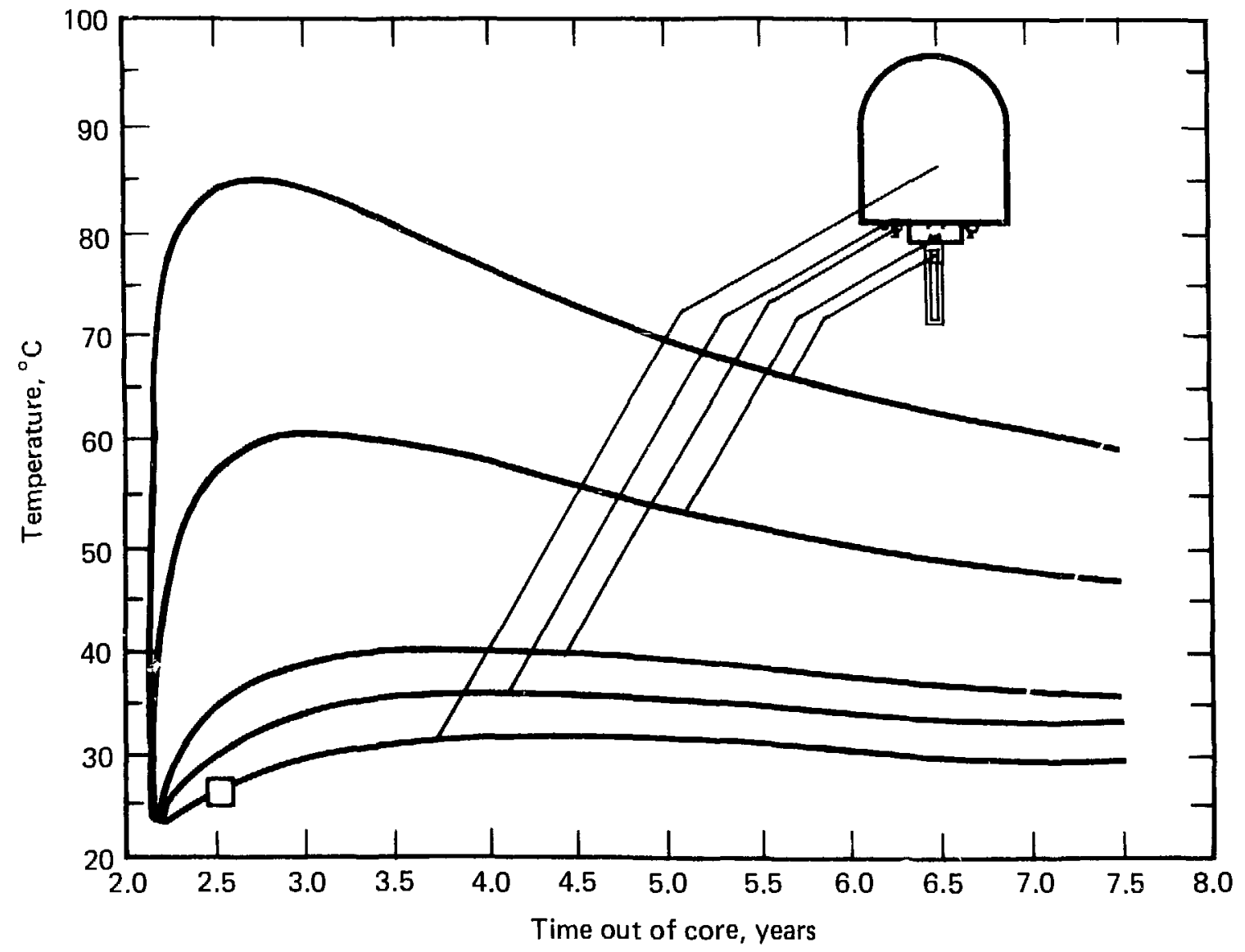

Figure 7. Three-dimensional TRUMP code calculations of temperature vs tine at indicated locations in storage drift (ventilation effects included). 


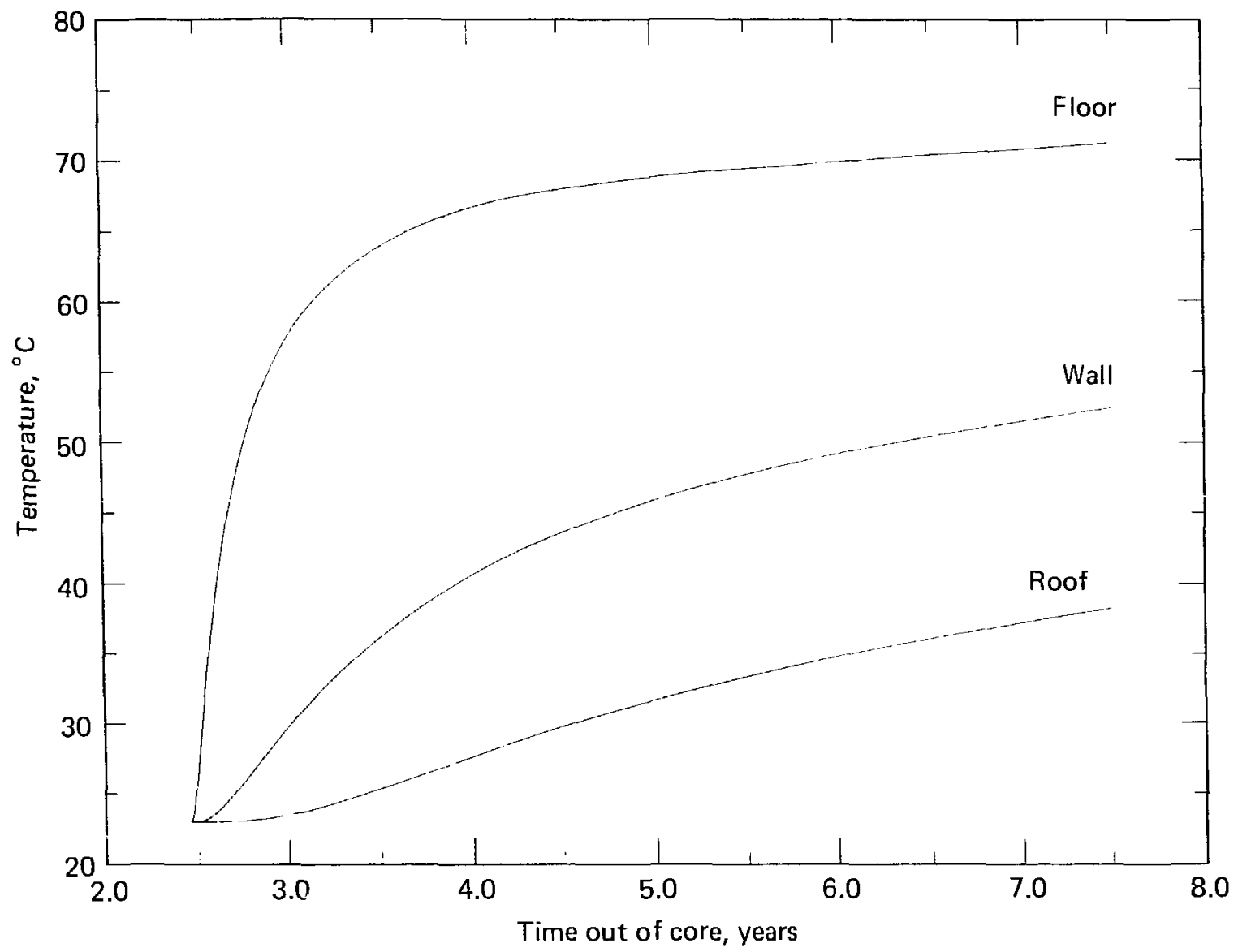

Figure 8. Temperature histories at selected locations (arift treated as insulator).

(Fig. 10) will make the drifts better conductors than the rock that was removed to create them. When radiation and convection are properly treated, the drjft surfaces are nearly isothermal and the nearby isotherms are nearly parallel to the surfaces.

Ventilation also has a profound effect on calculational results; the overall effect being a lowering of temperatures in and around the underground openings. The effect of changes in ventilation rate is shown in Fig. 11 . The two elevated temperature periods at about 3.3 and 3.7 years out of core are the result of reducing the quantity of air flowing through the facility by a factor of 2 and later returning to the previous rate. Such changes lead to rapid increases and decreases in temperature, respectively. In deciding on ventilation rates, calculations were made with ventilation varying over a wide 


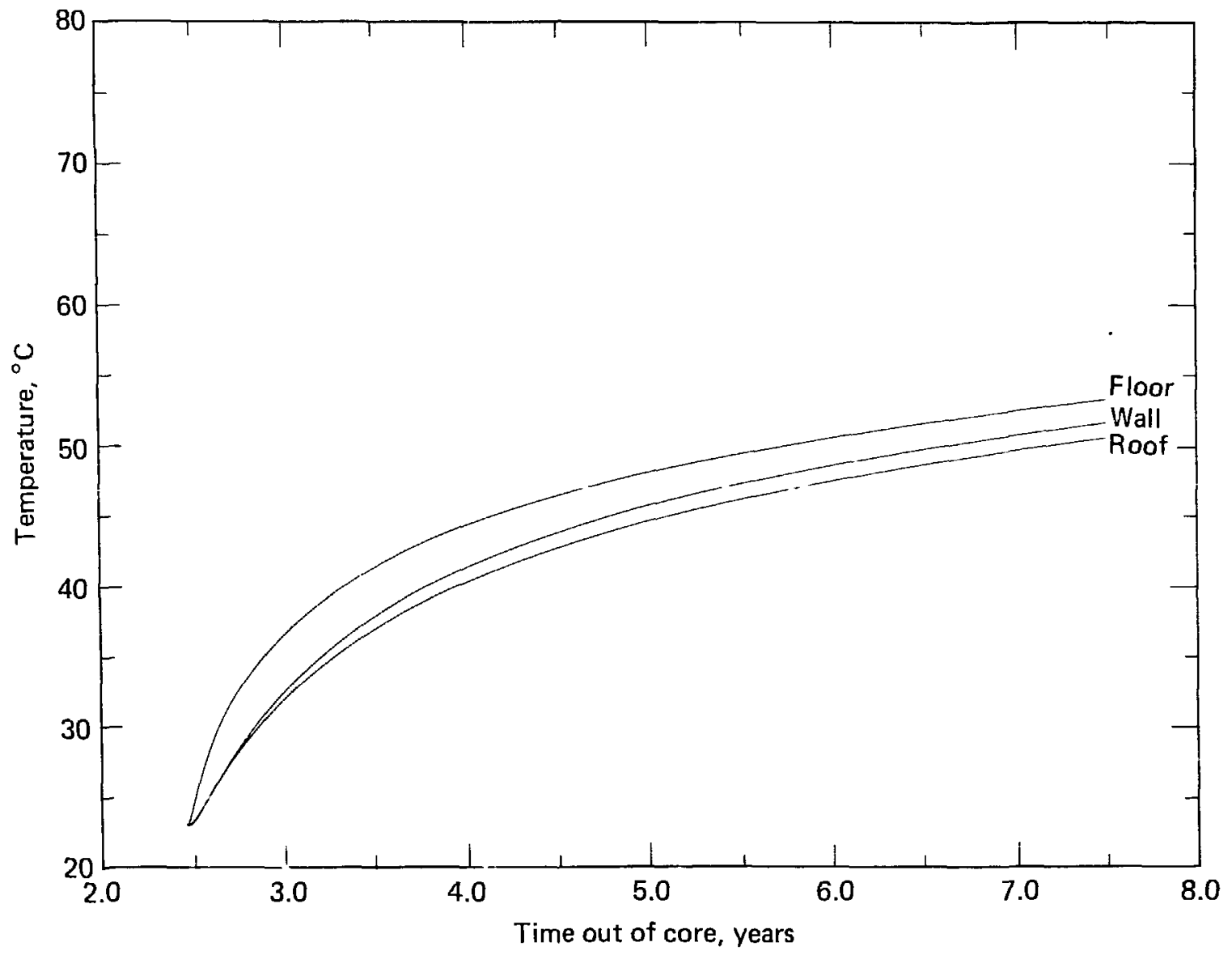

Figure 9. Temperature histories at selected locations (radiation only).

range (about 25-50 fold). Relationships were thus determined for temperature as a function of flowrate and position (Fig. 12). Actual flow rates were distributed according to the partial flow model discussed in section 3.2.

\subsection{Instrumentation Selection and Utilization}

The selection of temperature transducers for the SFT-C was supported by the thermal calculations since temperature ranges and sensitivities were used in choosing the Type $R$ thermocouples which are employed widely in the facility. 17

Transducer locations were selected by one or more of three criteria. First, the temperatures of certain physical locations are required for safety 


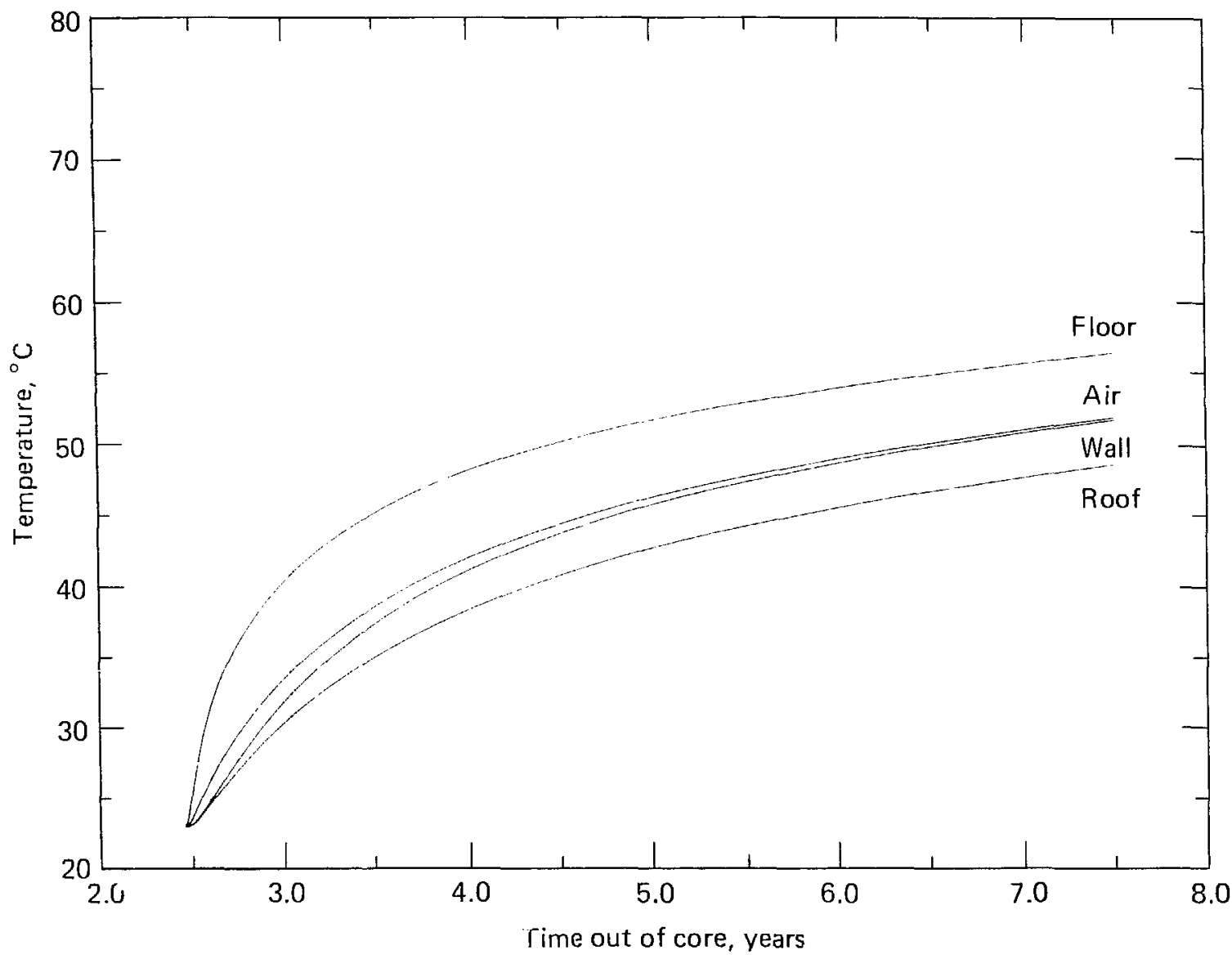

Figure 10. Temperature histories at selected locations (convection only).

or operator comfort. Examples are canister temperature, from which cladding temperature is inferred, and drift air temperature, respectively. Second, some temperature measurements in the very near-field are used to document differences in power levels of canisters and electrical simulators. Third, near-field and intermediate-field temperature measurements are used to correct other instruments for thermal expansion. 17

The temperature transducer array resulting from the three criteria given above, with minor augmentation, includes over 500 temperature measuring devices. In addition to meeting their primary functions listed above, they provide sufficiently dense data to validate the calculational techniques and codes against this very large problem. 


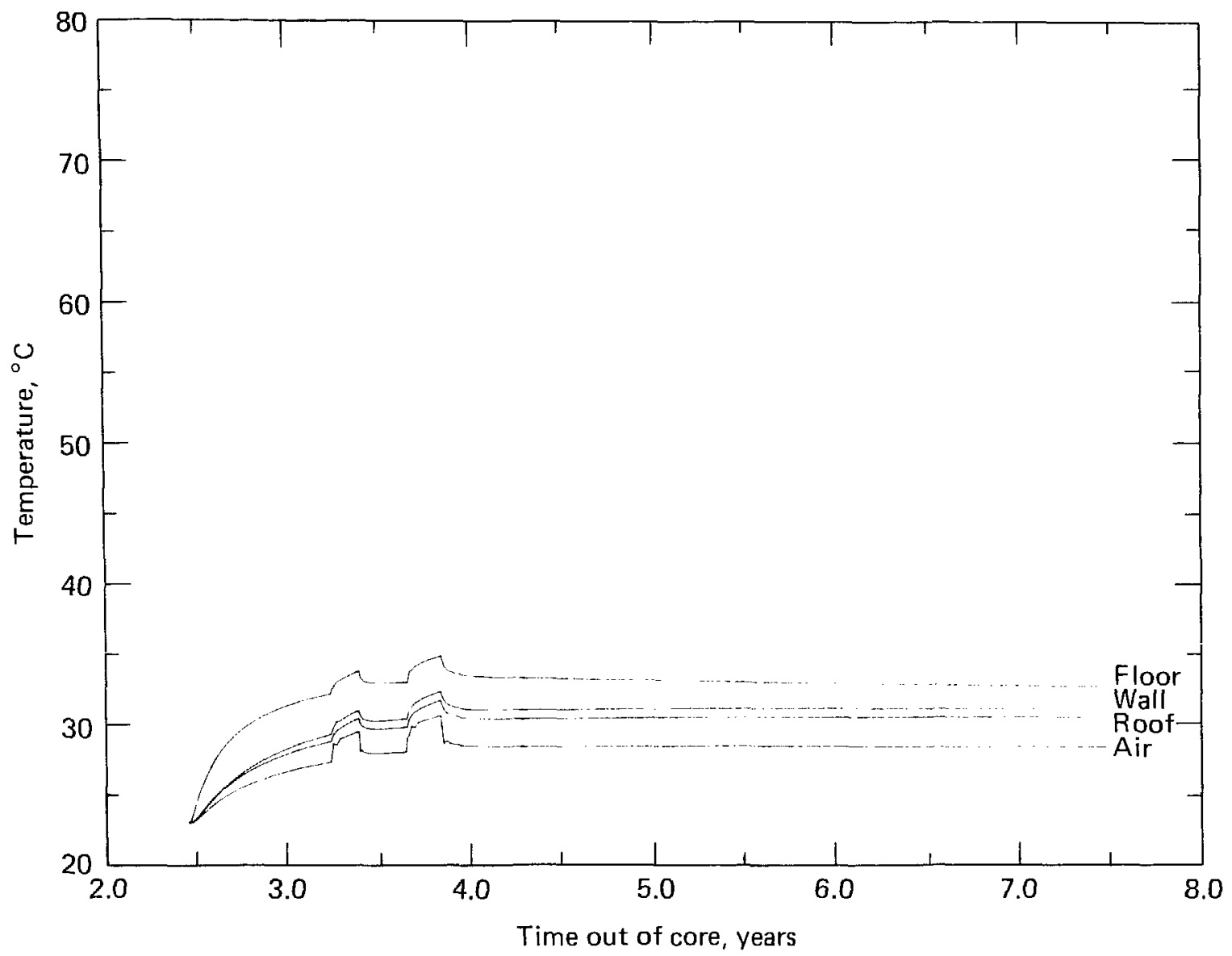

Figure 11. Temperature hiscories at selected locations (radiation, convection, and ventilation included).

Figure 12. Temperature for various desian ventilation rates as a function of distance along storage drift.

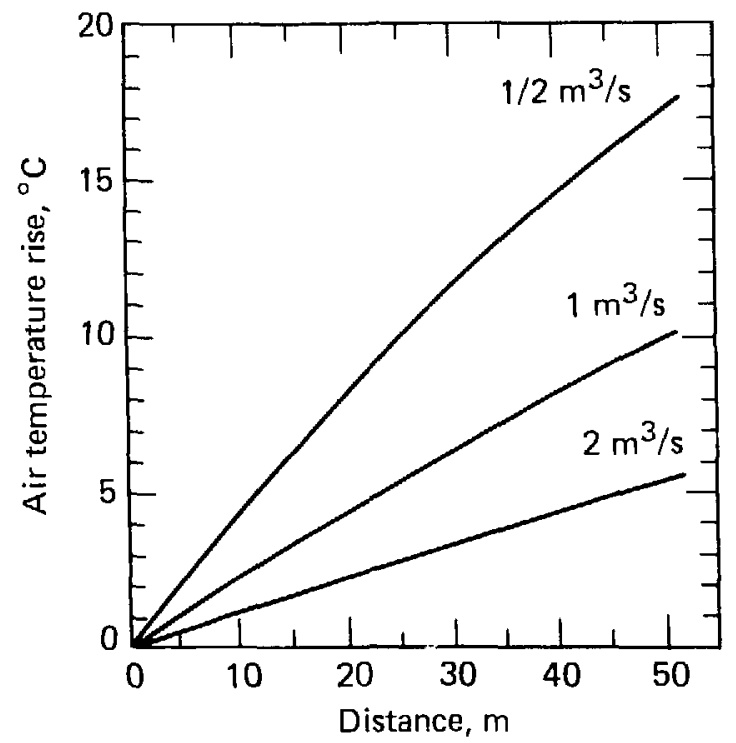


Instrument scan rates were largely selected based on empirical knowledge of heat transfer rates. The calculations do support the chosen rates and have proven useful in adjusting scan rates to observe transients caused by canister exchanges and ventilation rate changes.

\section{AS-BUILT TEST GEOMETRY}

Many changes in drift dimensions, material properties, power levels, and ventilation rates occurred during the design and construction of the SFT-C. ${ }^{18}$ The current best-estimates of all of these parameters were employed in the asbuilt thermal calculations.

\subsection{Spent Fuel Test Layout:}

The layout of the facility is shown in Fig. 13. A 3.7- $\times 3.7-\mathrm{m}$ access drift enters the railcar storage room, which is $14.6 \times 6 \times 7.6 \mathrm{~m}$ high. Beyond

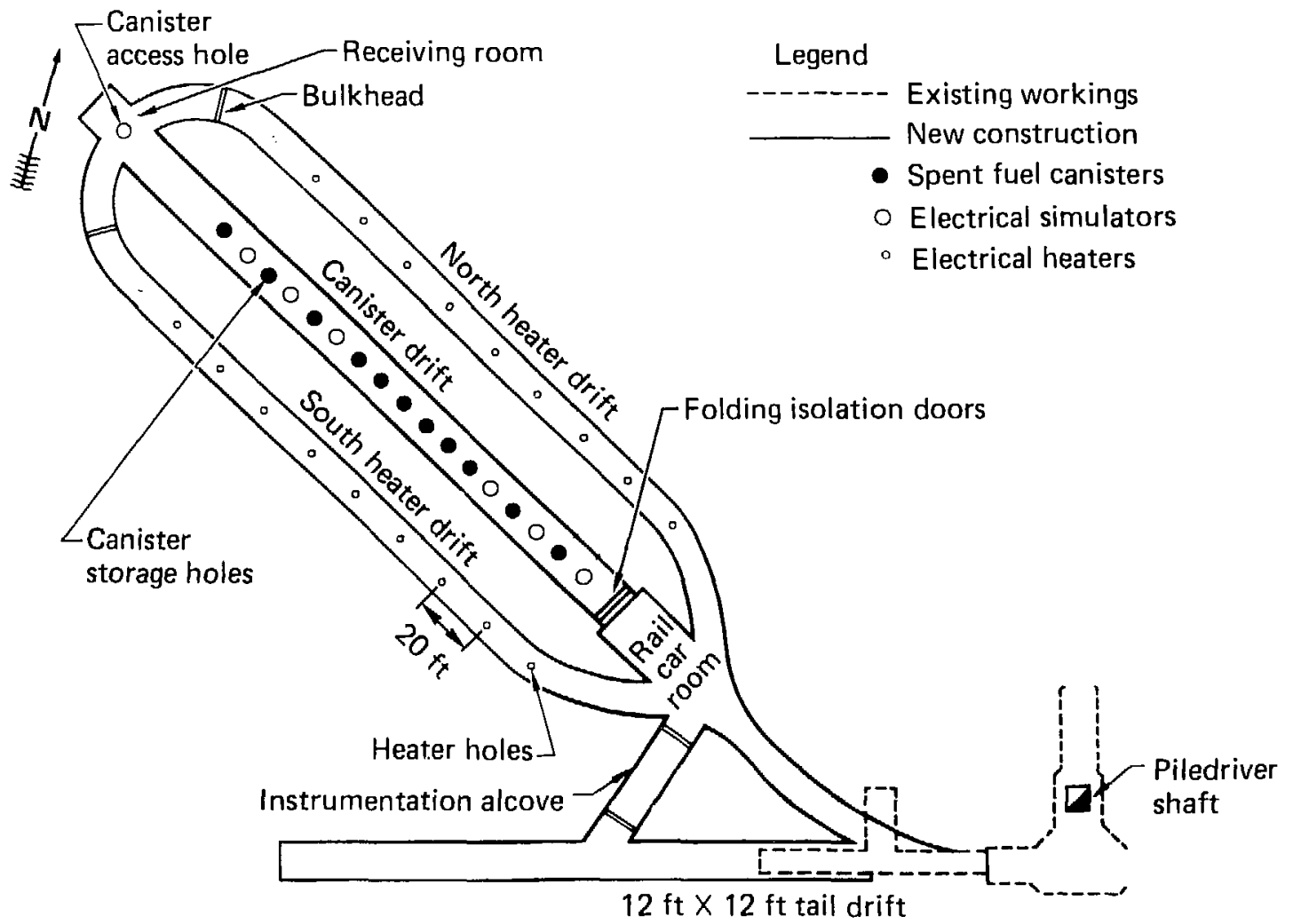

Eigure 13. Plan view of SFT-C as-built configuration. 
this room, the canister storage drift $6.1 \mathrm{~m}$ high by $4.6 \mathrm{~m}$ wide extends $64 \mathrm{~m}$ to the receiving area at the bottom of a 762-mm-diameter access hole with a 485-mm-i.d. casing. The spent fuel canisters were lowered from the surface through this access hole. A set of tracks for the railcar run from the access hole to the railcar storage room. The spent fuel canisters are stored in a linear array of vertical holes located between the rails at a spacing of $3 \mathrm{~m}$. Seventeen storage holes are provided in the canister storage drift. of these, 11 are used for spent fuel, and 6 for electrical simulators. An additional hole is located in the railcar room and is used to store an unheated dummy canister used for training personnel and evaluating handling equipment. The holes themselves are $610 \mathrm{~mm}$ in diameter and $5.2 \mathrm{~m}$ deep, with a 457-mm mild steel liner. The active length of the spent fuel assemblies and electrical simulators is about $3.66 \mathrm{~m}$, centered about $3.6 \mathrm{~m}$ vertically below floor level. Details of the emplacement geometry are shown in Fig. 14.

The north and south heater drifts measure $3.4 \times 3.4 \mathrm{~m}$ and have been excavated on either side of and parallel to the canister storage drift. Their spacing of $9.8 \mathrm{~m}$ and $10.2 \mathrm{~m}$ from the storage drift resulted from adjustment of the storage drift to center on the drilled access hole after the location of this hole was verified following mining of the heater drifts. Electrical resistance heaters with a diameter of approximately $19 \mathrm{~mm}$ were placed in these heater drifts at $6-\mathrm{m}$ intervals in small holes in the floor. The active length of these heaters is about $2 \mathrm{~m}$ and they are centered about $4 \mathrm{~m}$ below floor level.

It is important to recognize that exact drift shapes were not used in the calculations, nor should they be required. For ease of mesh generation and treatment of the complexities of thermal radiation, rectangular opening shapes were selected. Opening size was adjusted in the calculation to provide the proper air flow rates in the three-drift array.

\subsection{Material Properties}

The best available material properties were used in the as-built calculations. Thermal conductivity of the rock has been determined by several researchers to range from 2.62-3.38 $\mathrm{w} / \mathrm{m}-\mathrm{K}$, over a range of temperatures and pressures. $^{19-21}$ The most recent study ${ }^{21}$ examines the effects of both pressure and temperature on thermal conductivity. This study indicates that, although there was substantial variability, conductivity increases with 


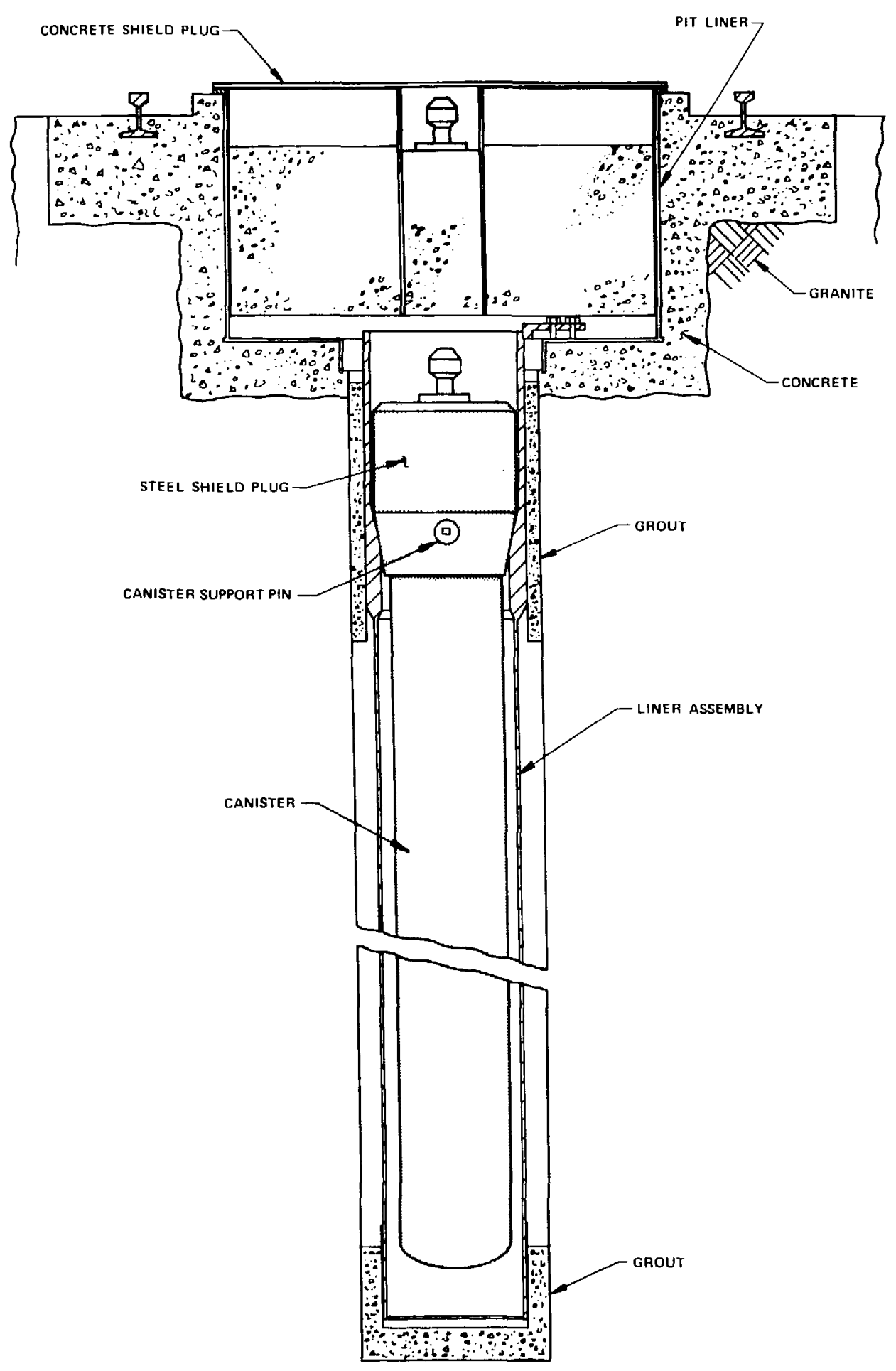

Figure 14. Detail of spent-fuel-storage configuration (Westinghouse Advanced Energy Systems, Pittsburgh, PA--Drawing number 615339-1B). 
increasing pressure at a given temperature and decreases with increasing temperature at a given pressure. For the range of expected field temperatures and pressures, a conductivity of $2.8-3.2 \mathrm{w} / \mathrm{m}-\mathrm{K}$ is indicated. Thermal diffusivity measurements indicated similar variability with values ranging from about $0.9-1.6 \mathrm{~mm}^{2} / \mathrm{s}$. In situ testing in the Climax stock initially indicated a value of $3.05 \mathrm{w} / \mathrm{m}-\mathrm{k}^{1,11}$ which has been increased to $3.11 \mathrm{~W} / \mathrm{m}-\mathrm{K}$ based on postiost transducer calibrations. ${ }^{22}$ These measurements also yielded a thermal diffusivity of $1.26 \mathrm{~mm}^{2} / \mathrm{s}$. Handbook values were used for all other thermal properties since materials such as air and various steels have well-documented thermal properties. Table 2 lists the properties used in the TRUMP calculations. Note that heat capacities and densities, rather than diffusivities, are used in the code. These parameters are related by the equation:

$\kappa=\frac{k}{\rho c_{p}}$,

where $x$ is diffusivity, $k$ is conductivity, $\rho$ is density, and $c_{p}$ is constant pressure heat capacity, in any compatible set of units. Convection is modeled using the previously discussed relationship between the Nusselt number, $\mathrm{N}_{\mathrm{Nu}}$ and the Rayleigh number, $\mathrm{N}_{\mathrm{Ra}}$ '

$\mathrm{N}_{\mathrm{Nu}}=0.13\left(\mathrm{~N}_{\mathrm{Ra}}\right)^{1 / 3}$

Table 2. Summary of thermal properties used in SFT-C as-built calculations.

\begin{tabular}{lcccc}
\hline & $\begin{array}{c}\text { Conductivity, } \\
\text { Component material }\end{array}$ & $\begin{array}{c}\text { Density, } \\
\mathrm{Mg} / \mathrm{m}^{3}\end{array}$ & $\begin{array}{c}\text { Heat capacity, } \\
\mathrm{J} / \mathrm{Kg}-\mathrm{K}\end{array}$ & Emittance \\
\hline Rock & 3.11 & 2650 & 930 & 0.8 \\
Air & 0.03 & 1 & 1000 & -- \\
Canister (stainless steel) & -- & -- & -- & 0.4 \\
Hole liner (mild steel) & - & -- & -- & 0.8 \\
Zircalloy cladding & -- & -- & -- \\
Helium filling & $4 \times 10^{-4} / \mathrm{T}^{\mathrm{a}}$ & -- & -- & -- \\
\hline a $\mathrm{T}=$ absolute temperature in degrees Kelvin. & &
\end{tabular}




\subsection{Thermal Sources}

Thirteen spent fuel assemblies were acquired for use in the SFT-C. These assemblies were obtained from the Florida Light and Power Company Turkey Point Unit \#3, a 666-MWe nuclear power plant located near Miami, Florida. The assemblies were removed from the reactor core in November 1977, after a calculated burnup of approximately 28,000 MWD/MTU.

The fuel assemblies were encapsulated in 356-mm (i4-in.) diameter stainless steel canisters that were welded closed and backfilled with 1-atm helium prior to shipment to the SFT-C. The decay heat level of the assemblies, based on the calculated decay heat curve normalized to the calorimeter-measured values, is shown as the smooth curve in Fig. 15. Details of the measured (calorimetry) and calculated decay heat for these assemblies

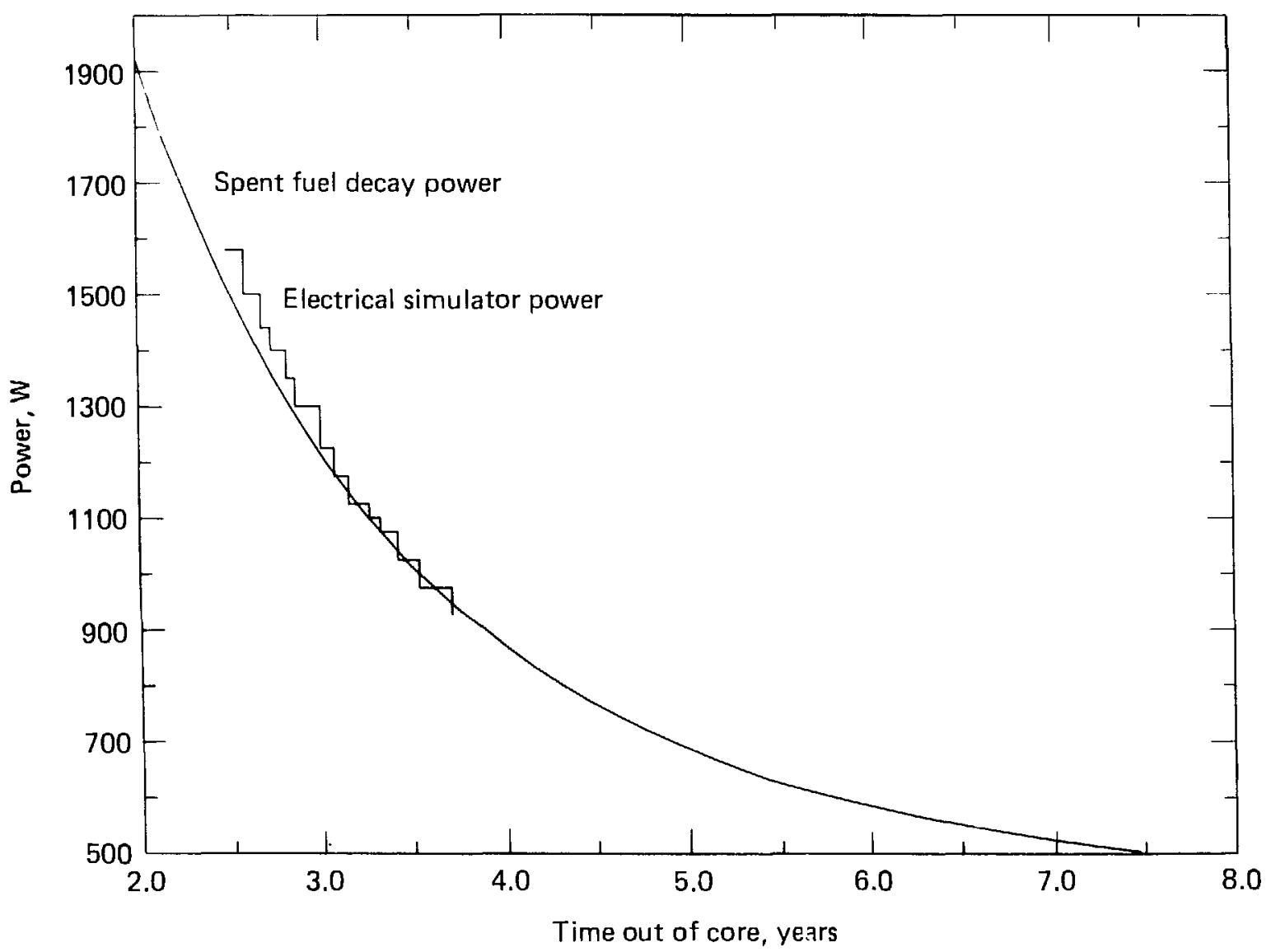

Figure 15. Spent fuel and electrical simulator power histories. 
are presented elsewhere. ${ }^{23}$ The curve indicates an output of $1564 \mathrm{~W}$ at emplacement of the first canister in the SFT-C on April 18, 1980.

Eleven spent fuel assemblies were installed in the SFT-C test array during the period of April 18 to May 28, 1980 at a rate of two assemblies per week (Table 3). All calculations key off the mean emplacement date (May 6 , 1980) and mean power level on that date (1530 W/assembly at 2.46 years out of core). The remaining two assemblies will be utilized in a series of fuel-assembly exchanges scheduled periodically during the test. The first such exchange was conducted in mid-January 1981.

A second major source of heat is the set of six electrical simulators interspersed with the spent fuel canisters in the canister drift (Fig. 1). Each simulator consists of four tubular electrical resistance heating elements in a baffled and shrouded framework and is contained within a canister that is identical to those used for spent fuel encapsulation. These units are thus thermally similar to the spent fuel. The only significant difference is in the gas filling the void volume of the canister. As indicated earlier, the spent fuel canisters are filled with helium at $\sim 1$ atm. The electrical simulators are air-filled. In the calculations, no difference between spent fuel assemblies and electrical simulators was considered.

Each simulator was energized at $1580 \mathrm{~W}$ at the time its corresponding fuel assembly was installed in its position. Adjustments to power were made subsequent to installation to match the decay of the spent fuel (Fig. 15). Improved calculations and measurements of spent fuel power output resulted in a somewhat cooler decay curve, as discussed previously. Simulator power, which was based on earlier calculations, is thus a few percent higher than that of the spent fuel (Fig. 15). Further adjustments are planned to decrease the observed differences.

Ten guard heaters in each of two parallel heater drifts provide the third major source of heat. The power levels of these electrical resistance heaters are controlled to provide thermal boundaries on the repository model cell which closely approximate those of a large repository. Table 4 gives the power history for the guard heaters. The early power spike is not included in the thermal calculations. For the calculations, the 925-W power level begins on June $27,1980$.

Note that the equivalent years out of core are given for the guard heaters since the thermal calculations are timed according to the age of the spent fuel from removal from the reactor core. 
Table 3. Fuel assembly installation schedule.

\begin{tabular}{|c|c|c|c|}
\hline $\begin{array}{l}\text { storage } \\
\text { hole (CEH) }\end{array}$ & $\begin{array}{l}\text { Fuel assembly } \\
\text { serial number }\end{array}$ & $\begin{array}{l}\text { Installation } \\
\text { date }\end{array}$ & Comment \\
\hline 1 & D34 & $4 / 25 / 80$ & Calorimetered $4 / 1 / 80$ at $1550 \mathrm{w}$ \\
\hline 2 & -- & $4 / 22 / 80$ & Electrical simulators \\
\hline 3 & $\mathrm{D} 40$ & $4 / 18 / 80$ & \\
\hline 4 & -- & $5 / 06 / 80$ & Electrical simulators \\
\hline 5 & $\mathrm{D} 46$ & $4 / 29 / 80$ & \\
\hline 6 & -- & $5 / 01 / 80$ & Electrical simulators \\
\hline 7 & D06 & $5 / 13 / 80$ & MIT assembly ${ }^{a}$ \\
\hline 8 & Dl6 & $5 / 20 / 80$ & \\
\hline 9 & $\mathrm{D} 47$ & $5 / 08 / 80$ & \\
\hline 10 & D01 & $5 / 15 / 80$ & MIT assembly \\
\hline 11 & D0 4 & $5 / 28 / 80$ & $\begin{array}{l}\text { MIT assembly, calorimetered } \\
5 / 20 / 80 \text { at } 1385 \mathrm{~W}\end{array}$ \\
\hline 12 & D09 & $5 / 01 / 80$ & \\
\hline 13 & -- & $4 / 29 / 80$ & Electrical simulators \\
\hline 14 & D35 & $5 / 06 / 80$ & \\
\hline 15 & -- & $4 / 18 / 80$ & Electrical simulators \\
\hline \pm 6 & Dl8 & $4 / 22 / 80$ & \\
\hline 17 & -- & $4 / 25 / 80$ & Electrical simulators \\
\hline (E-MAD) & D15 & & Calorimetered $7 / 8 / 80$ at $1423 \mathrm{~W}$ \\
\hline (E-MAD) & D2.2 & & Calorimetered $7 / 9 / 80$ at $1284 \mathrm{~W}$ \\
\hline
\end{tabular}

a "MIT" refers to Material Interaction Tests performed by Hanford Engineering Development Laboratory personnel. ${ }^{17}$

Table 4. Power levels for 20 guard heaters in SFT-C north and south heater drifts.

\begin{tabular}{lcc}
\hline Date & Time out of core, years & Power 1evel, W \\
\hline June 27, 1980 & 2.60 & 1850 \\
July 2, 1980 & 2.62 & 525 \\
December 15, 1980 & 3.07 & 1250 \\
March 9, 1982 & 4.30 & 1350 \\
\hline
\end{tabular}


Each of the three drifts in the test area is equipped with electric lights, which when turned on contribute a significant addition to the thermal load of the test. Within the canister storage drift, for example, 22 quartz iodide lights are installed--at $500 \mathrm{~W}$ each, a thermal load of $11 \mathrm{~kW}$. The normal test configuration is for the lights to be turned off; therefore, these sources are not included in the calculations. However, when personnel are present in the test area, the lights are turned on, and the additional heat load is reflected in the air temperature. This additional load has been energized an average of about eight hours per week over the past several months.

\subsection{Ventilation System}

Air flow through the SFT-C is controlled by louvered, bulkheaded doorways at the northwest end of each heater drift and at the railcar room near the southeast end of the canister drift (Fig. 13). Flowrate is measured at ground surface in the exhaust airstream with a turbine-type flowmeter. Measurements in each drift were used to set the louvers so that $50 \%$ of the total flow passes through the canister drift and $25 \%$ of the total flow passes through each heater drift.

A nominal total flowrate of $2 \mathrm{~m}^{3} / \mathrm{s}$ was planned to allow reasonably comfortable working conditions in the drifts. The nominal flowrate was implemented in the design calculations by using the partial flow model discussed in Section 3.2. Given a total as-built flow rate of $2.65 \mathrm{~m}^{3} / \mathrm{s}$, we calculate for the canister drift:

$$
\begin{aligned}
& \dot{V}^{\prime}=\frac{\text { flowrate }}{(\text { no. of canisters) } \times \text { (canister spacing) }} \\
& \dot{V}^{\prime}=\frac{1.325 \mathrm{~m}^{3} / \mathrm{s}}{(17)(3 \mathrm{~m})}=0.026 \mathrm{~m}^{2} / \mathrm{s} .
\end{aligned}
$$

For each heater drift, the partial flow is half this value or $0.013 \mathrm{~m}^{2} / \mathrm{s}$. Peduction in the flowrate was planned to occur twice during the test to. examine the response of the SFT-C to deviations in ventilation and related temperature changes. These reductions have been included in the calculations and will be discussed in Section 6 . 
Two- and three-dimensional TRUMP calculations were performed using the best-available data presented in Section 5. Analytical solutions served an important role in SFT-C design but were not repeated for the as-built geometry because many features of the actual test facility cannot be included in analytical models.

Meshes used in these calculations are as described in Section 4. All boundaries were treated as adiabatic in the as-built TRUMP calculations. The appropriateness of this boundary condition was verified by checking changes in boundary-zone temperatures at the end of the calculation. These zones experienced increases in temperature of $0-0.02^{\circ} \mathrm{C}$.

All calculations were performed to include a period of five years after spent fuel emplacement. All dates are based on fuel age out of core: 2.46 years at emplacement. Calculational results are, in general, presented according to physical location since test data are organized in this manner.

\subsection{Fuel-Rod-Cladding Temperature}

The temperature of the spent-fuel-rod zircalloy cladding was recalculateif to ascertain the factor of safety relative to the recommended peak cladding temperature of $380^{\circ} \mathrm{C}$. A spent-fuel-assembly cross section was treated as essentially a two-dimensional problem. The temperature of its enclosing canister, as calculated by TRUMP for the emplaced spent fuel assembly, established its external boundary condition. The power level of the fuel, established earlier by calorimetry, was also known.

Steady-state solutions for fuel rod temperature were then obtained for several pairs of known canister temperatures and fuel element power levels. These calculations permit bracketting the peak fuel element temperature and the time at which it oscurred during the test, about 2.55 years out of core.

A series of calculations was performed to establish the peak for several possible conditions. In all cases, thermal radiation was active. The emittance of zircalloy was taken as 0.4 . It is possible for the helium backfill to be absent (vacuum) or to be replaced by air. For either case, conduction was disallowed in the calculation. Another condition examined was asymmetry of the power distribution in the fuel assembly. 
Table 5 summarizes the results of this series of calculations and Fig. 16 shows the cladding temperature history while the spent fuel was in storage at the SFT-C. First, note that all temperatures are well below the maximum permissible zircalloy cladding temperature. This is to be expected since fuel power level is markedly lower than that assumed in the design calculations. Second, the effect of venting the helium backfill (due to a canister leak), and thereby greatly reducing the conductive component of heat transfer, is pronounced. A temperature increase of about $80^{\circ} \mathrm{C}$ should be anticipated. Third, the effect of ilightly asymmetric power distribution within a fuel assembly is minor. Fourth, although not shown in the table, increasing the emittance of the zircalloy will substantially reduce the peak cladding temperature. We believe that the emittance of the zircalloy may be as high as 0.8 but are awaiting confirming data before basing our calculations on this less conservative value.

Table 5. Calculated peak fuel rod cladding temperature for various conditions.

Power level $(W)$ and

distribution
Conduction
Approximate peak temperature $\left({ }^{\circ} \mathrm{C}\right)$

\begin{tabular}{lll}
\hline 1466, uniform & Yes & 236 \\
1466, asymmetric & Yes & 239 \\
1466, uniform & No & 316 \\
1466, asymmetric & No & 322 \\
\hline
\end{tabular}

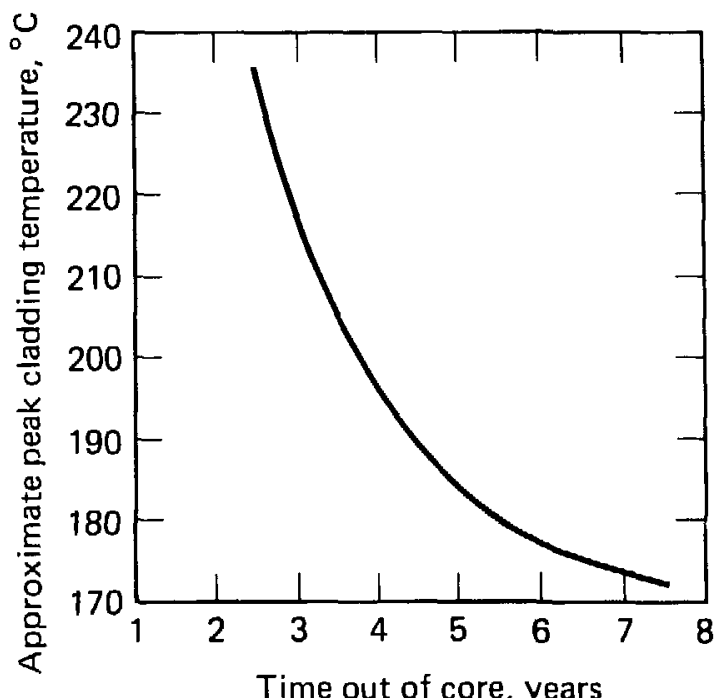

Figure 16. History of maximum cladding temperature for spent fuel aged 2.5 to 7.5 years out of core. 


\subsection{Air and Fixture Temperatures}

Two- and three-dimensional TRUMP calculations provided temperature histories throughout the test facility. Editing the output at selected locations and plotting the calculational results produce the required information.

Canister drift and heater drift air temperature histories show the pronounced effect of changes in ventilation rate (Fig. 17). The two time periods that display elevated temperatures coincide with reduction of the nominal ventilation rates by about a factor of 2 .

Several interesting aspects of ventilation are seen in Fig. 17. First, as discussed in section 4.3, ventilation removes a significant quantity of heat from the SFT-C, thereby markedly reducing temperatures, particularly near

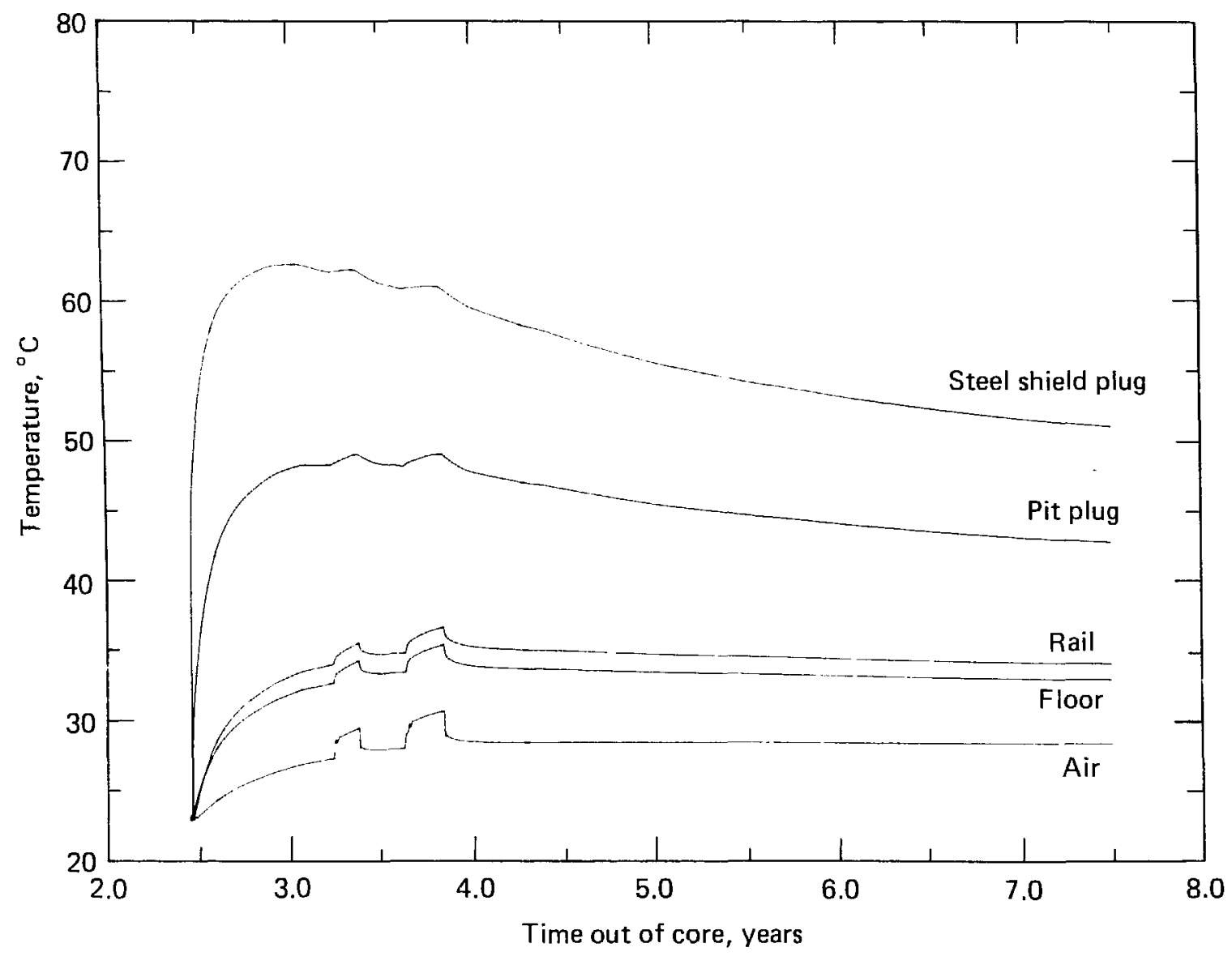

Figure 17. Calculated temperature histories of canister drift air and construction features. 
the ventilated openings. Second, reducing the ventilation leads to almost instantaneous increases in temperatures of the air and suriaces in close contact with the air. Points farther away from the ventilation air (the source of the thermal perturbation) sense the change later, in proportion to their respective time constants, $L^{2} / K$. Third, temperature-time gradient decreases with distance from the source of perturbation. This effect is seen by comparing the upper and lower curves (Fig. 17). The second and third points confirm that the conducting media, rock in this case, is a thermal filter in both time and space. The fourth point to be made concerns operations at the SFT-C. Air temperatures are sufficiently low to permit moderate work activities to be conducted in reasonable comfort. Pit floor and shield plug temperatures should be acceptable for operators involved in instrument emplacement and removal in this region.

\subsection{Near-Field Temperature Histories}

Temperature histories for the canister near-field environment are shown in Fig. 18. The curves show calculated temperatures at the midplane of the center spent fuel assembly. This region is most heavily instrumented in the SFT-C; 18 thermocouples are associated with each canister emplacement hole in this region.

The canister, liner, and the points $200 \mathrm{~mm}$ and $360 \mathrm{~mm}$ into the rock are instrumented directly. The two latter sets of thermocouples are used to calculate the rock wall temperatures during data reduction. A semilogarithmic relationship between temperature and distance from the canister centerline is suggested.

With regard to the effect of changes in ventilation rate discussed in Section 6.2, notice that this effect is almost imperceptiule in the canister near-field environment.

\subsection{Temperature Profiles}

The temperature histories presented in Section 6.3 are invaluable in examining thermal transients in the very-near-field environment. To present such histories for each of roughly 200 locations where temperature-measuring devices are present at the SFT-C would be a major effort and would, in the end, not present the nverall picture of thermal transport at the facility. To 


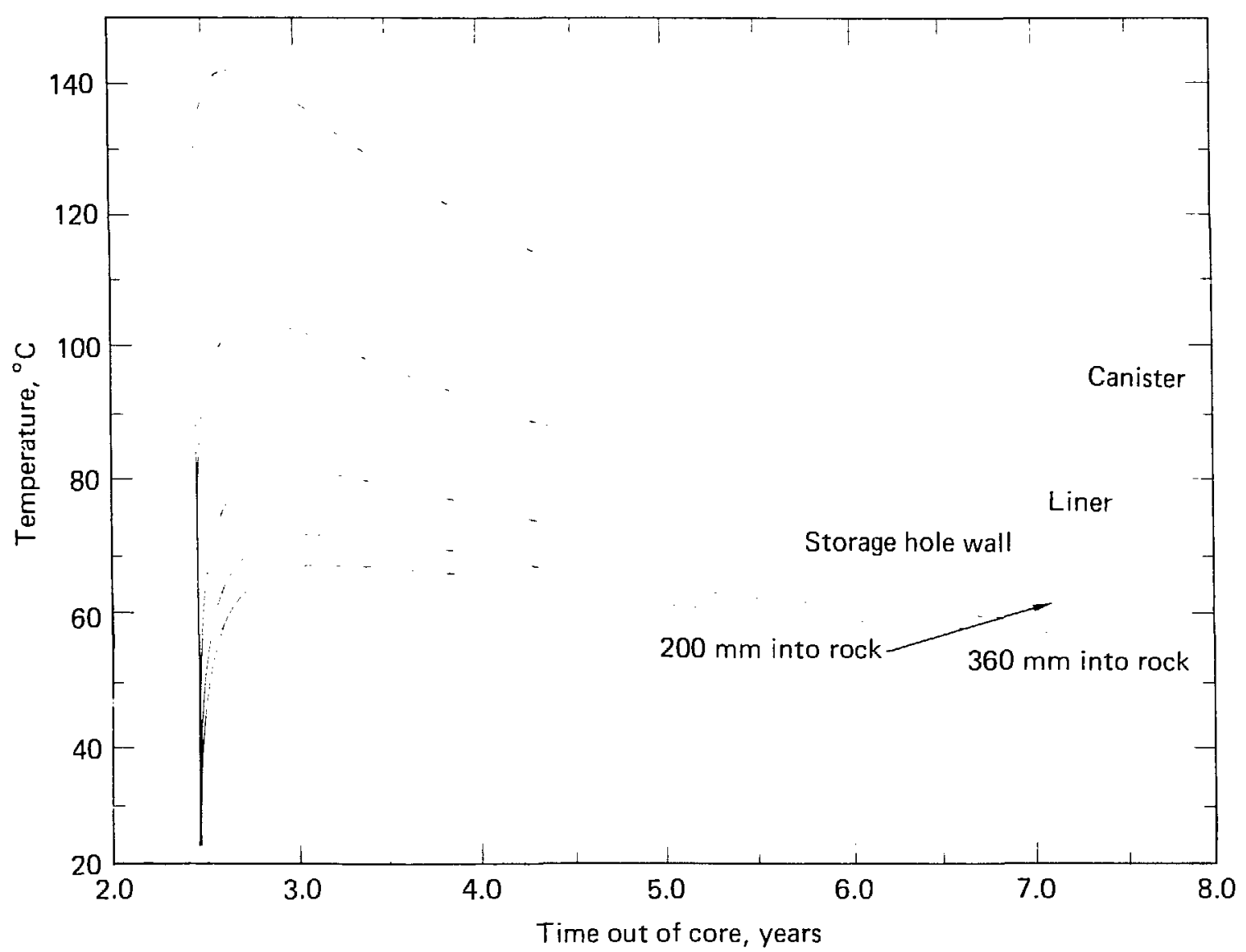

Figure 18. Calculated temperature histories of selected points in canister near-field environment.

overcome this problem, contour plots are developed for sieveral regions of interest in the SFT-C at various times of interest, typically half-year intervals.

Figures 19 through 29 show temperature contours for one half of the SFT-C geometry. Drifts are shown shaded and tick marks indicate a $5-m \times 5-m$ reference grid, not the calculational mesh. The contour interval is $2.5^{\circ} \mathrm{C}$ and the first solid contour is at $37.5^{\circ} \mathrm{C}$. Spent fuel insertion is based on the mean age at emplacement of 2.46 years out of core. Guard heater activation is at about 0.14 years into the test in accordance with section 5 . The plots cover the five-year time range of 2.5-7.5 years out of core, the expected life of the test. Measured temperatures at the times shown may De superposed on these cross sections to compare calculated and measured temperatures throughout the test array. 
TIME $=2.50$ YEARS
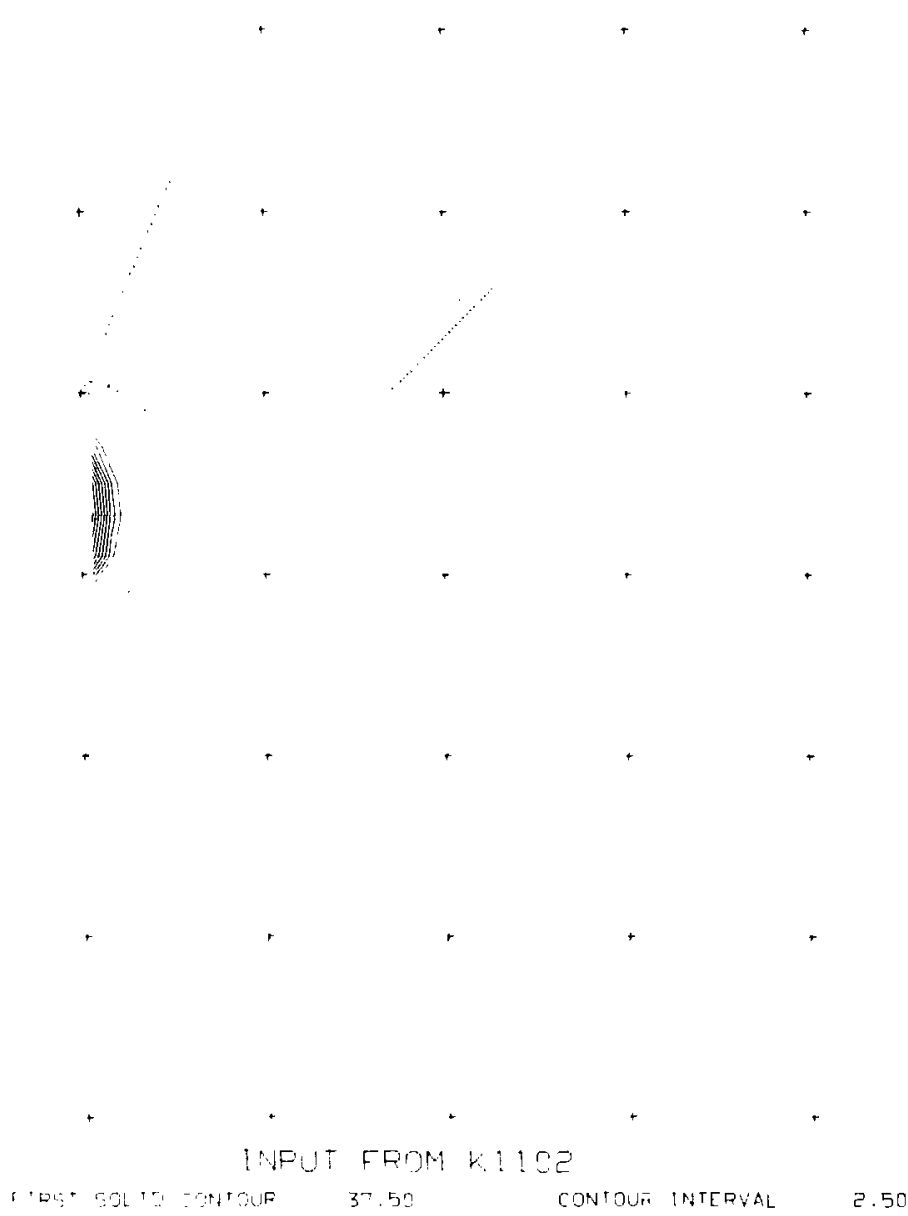

Figure 19. Temperature contours for SFT-C cross section at 2.50 years out of core; spent fuel was emplaced at 2.46 years out of core. 
Figure 20. Temperature contours for SFT-C cross section at 3.00 years out of core; spent fuel was emplaced at 2.45 years out of core. 
W M $=3.50$ it. i.PS

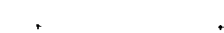

Figure 2l. Temperature contours for SFT-C cross section at 3.50 years out of core; spent fuel was emplaced at 2.46 years out of core. 


\section{THE N it. OS it ARES}

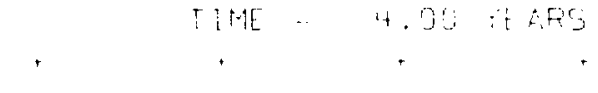
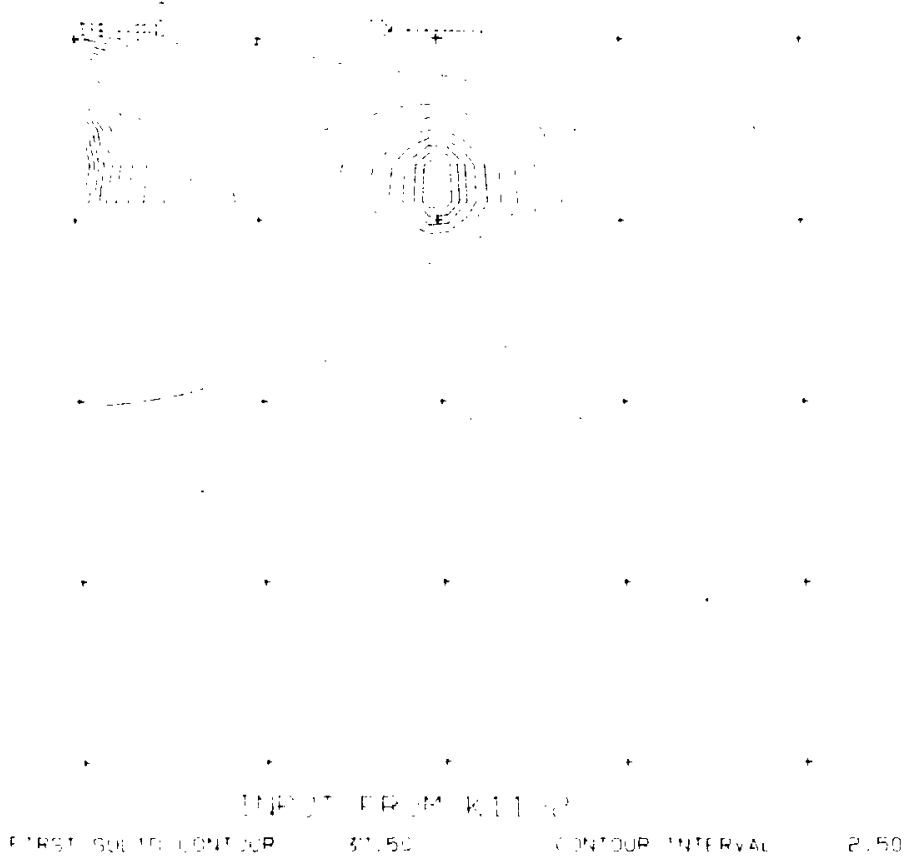

Figure 22. Temperature contours for SFT-C cross section at 4.00 years out of core; spent fuel was emplaced at 2.46 years out of core. 


\section{TINE = 4.5. IEARS}

$+\quad$ TIVE +.50 iEARS

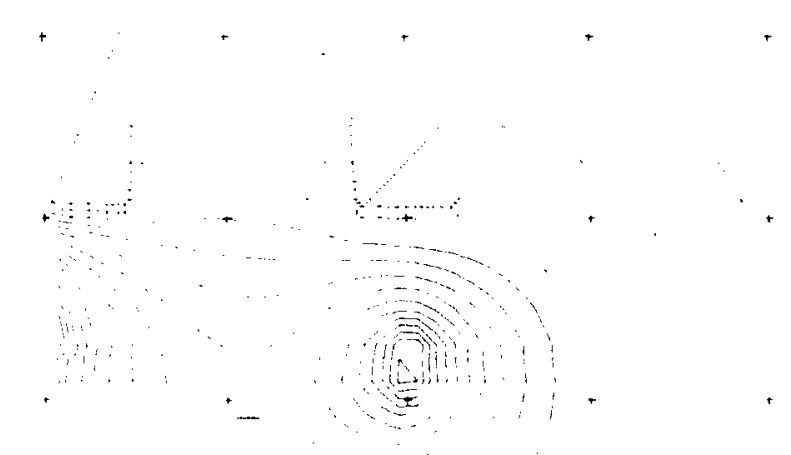

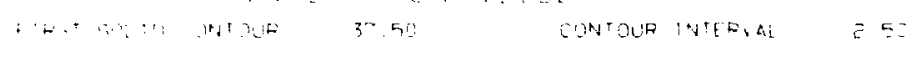

Figure 23. Temperature contours for SFT-C cross section at 4.50 years out of core; spent fuel was emplaced at 2.46 years out of core. 


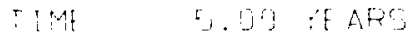
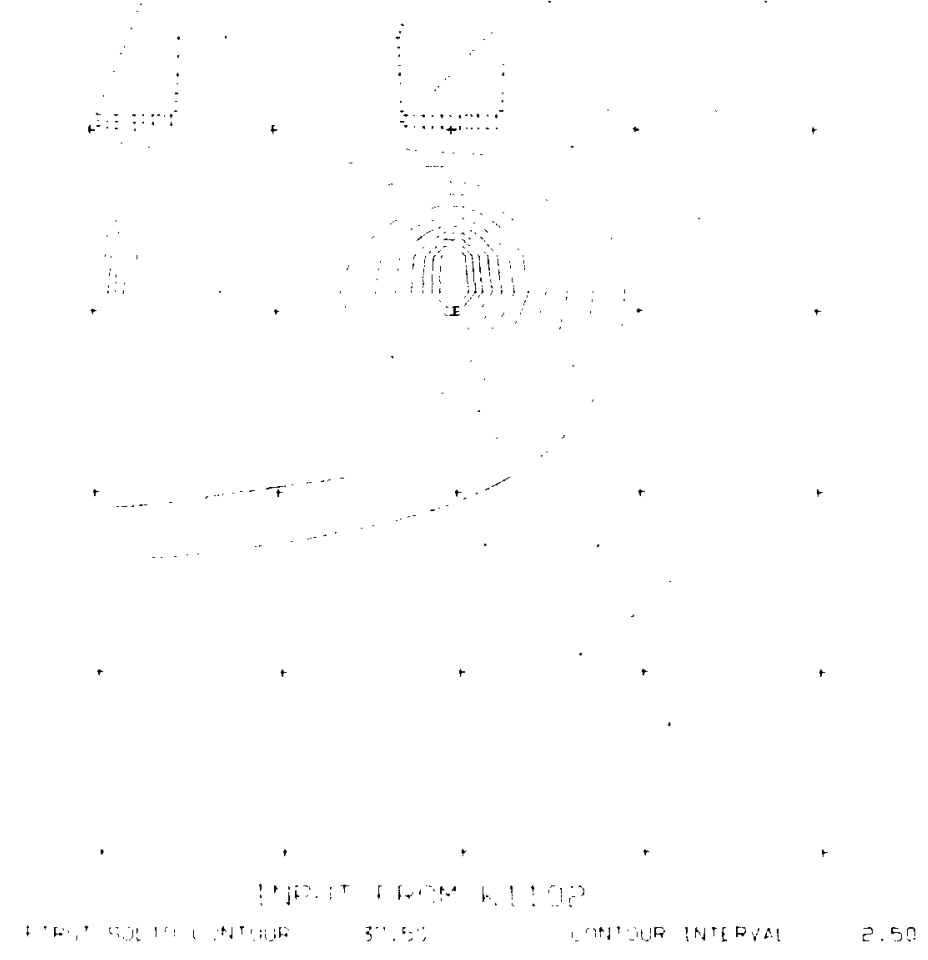

Figure 24. Temperature contours for SFT-C cross section at 5.00 years out of core; spent fuel was emplaced at 2.46 years out of core. 


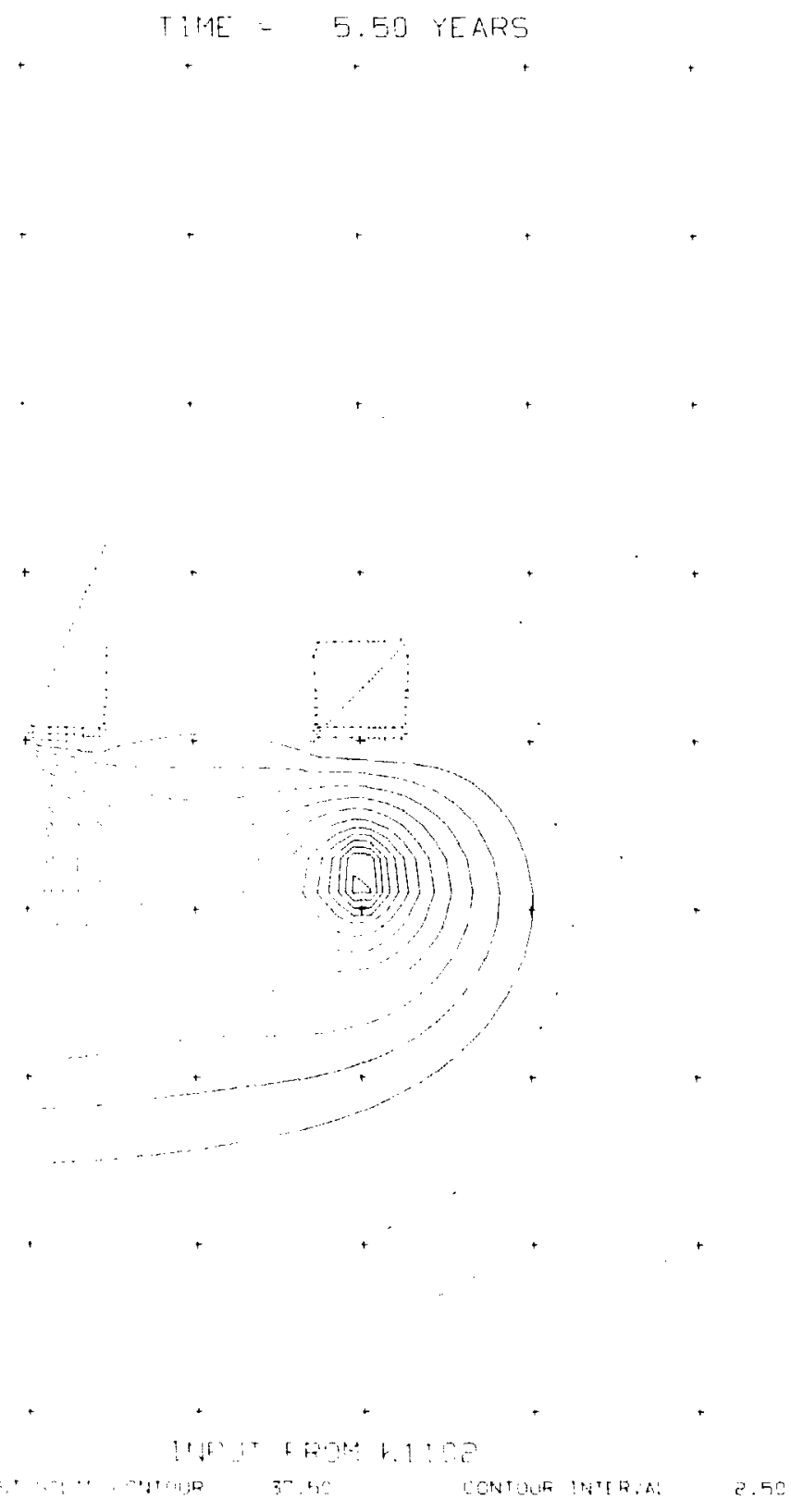

Figure 25. Temperature contours for SFT-C cross section at 5.50 years out of core; spent fuel was emplaced at 2.46 years out of core. 
TME = G.OTY YARS

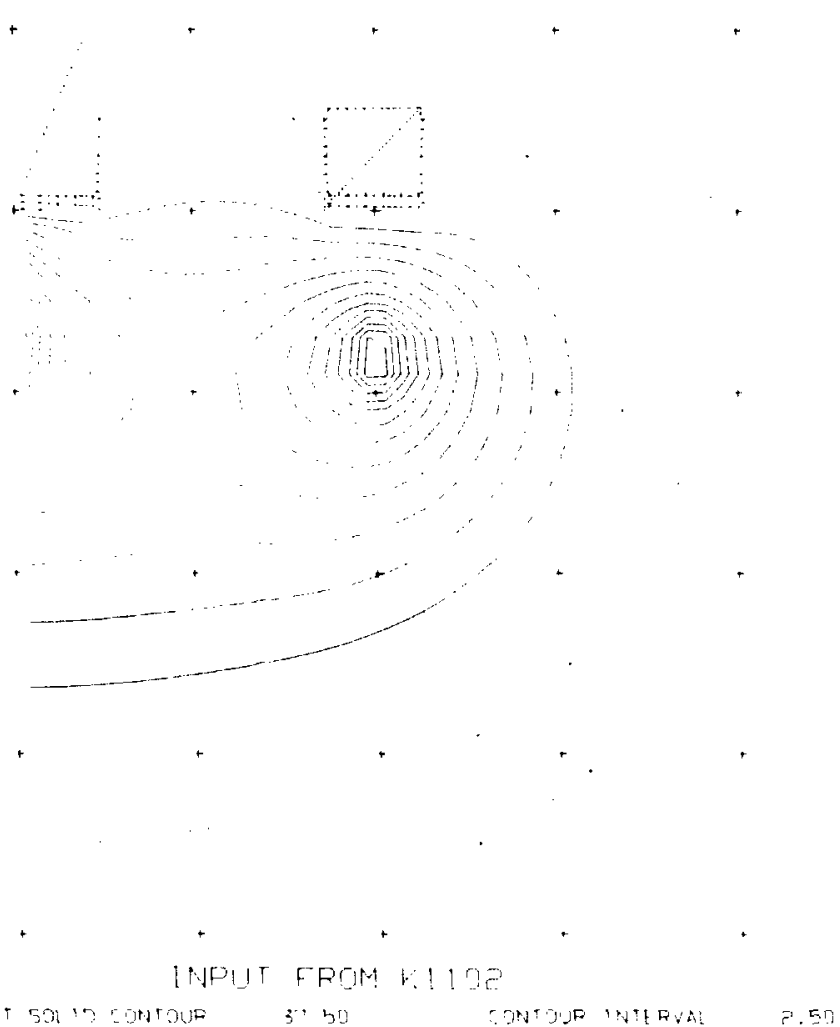

Figure 26. Temperature contours for SFT-C cross section at 6.00 years out of core; spent fuel was emplaced at 2.46 years out of core. 
THE E. FO YEARS
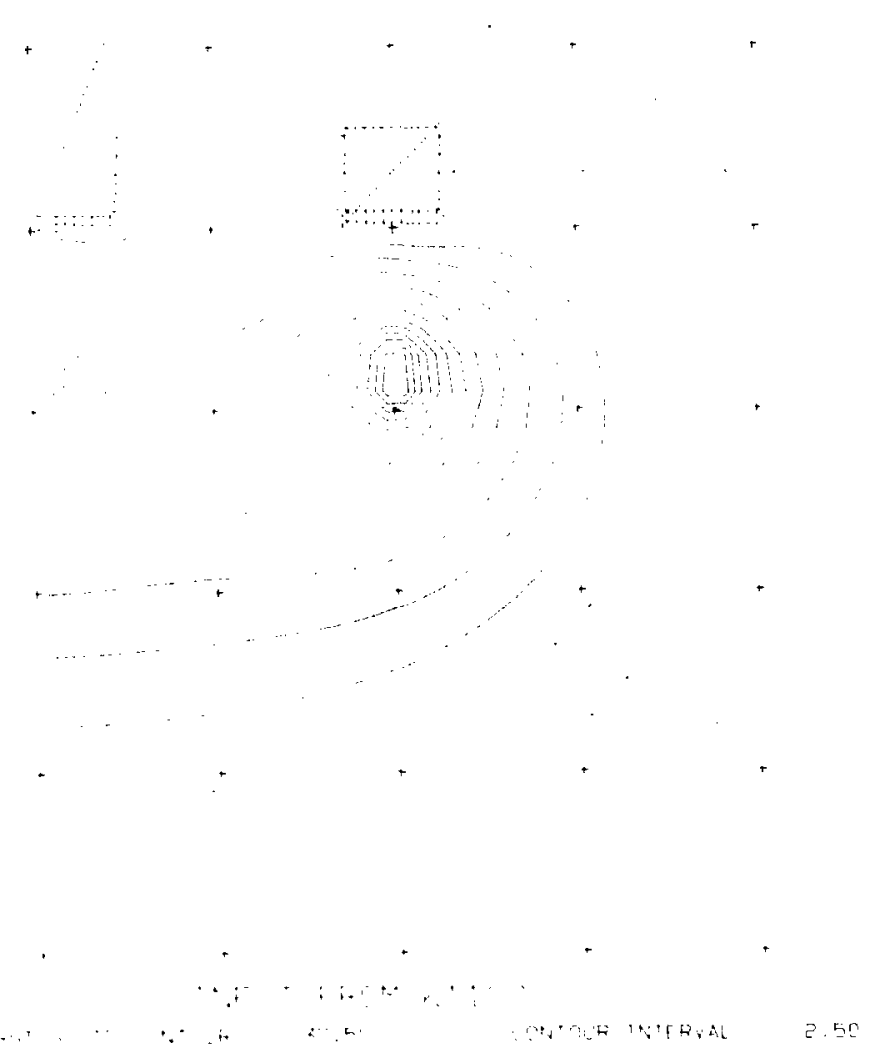

Figure 27. Temperature contours for SFT-C cross section at 6.50 years out of core; spent fuel was emplaced at 2.46 years out of core. 


\section{TIME = 7.00 it ARS}

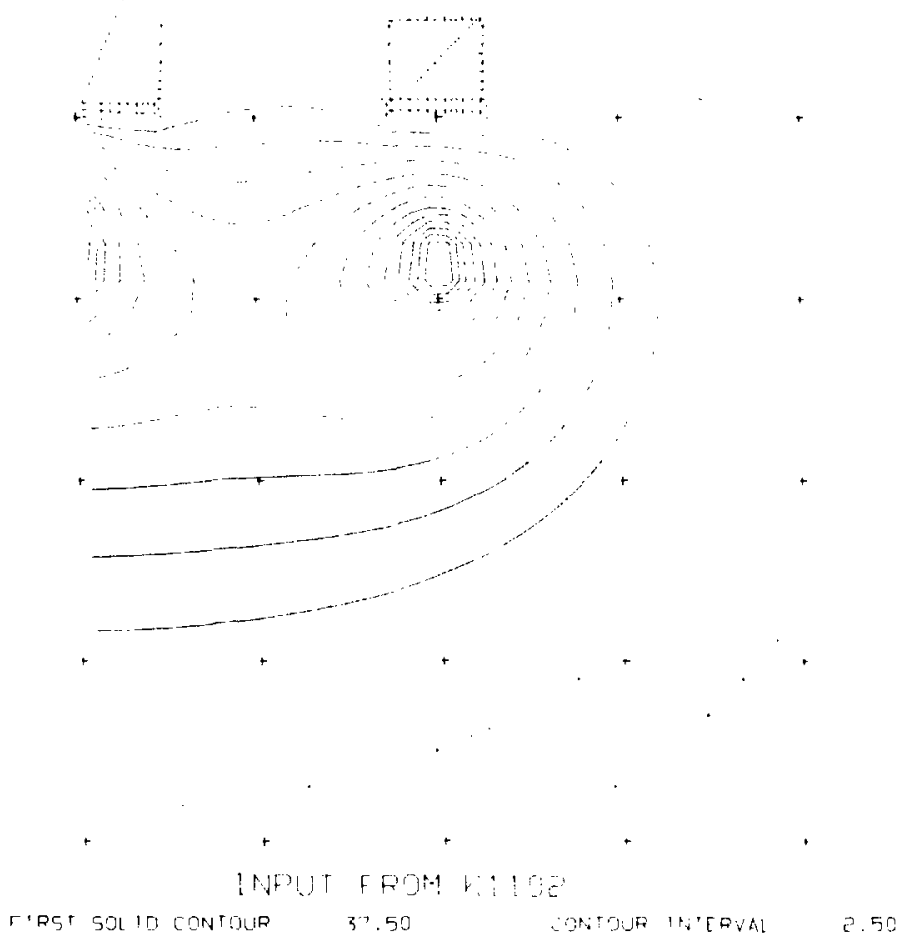

Figure 28. Temperature contours for SFT-C cross section at 7.00 years out of core; spent fuel was emplaced at 2.46 years out of core. 
TIME $=7.50$ YEARS

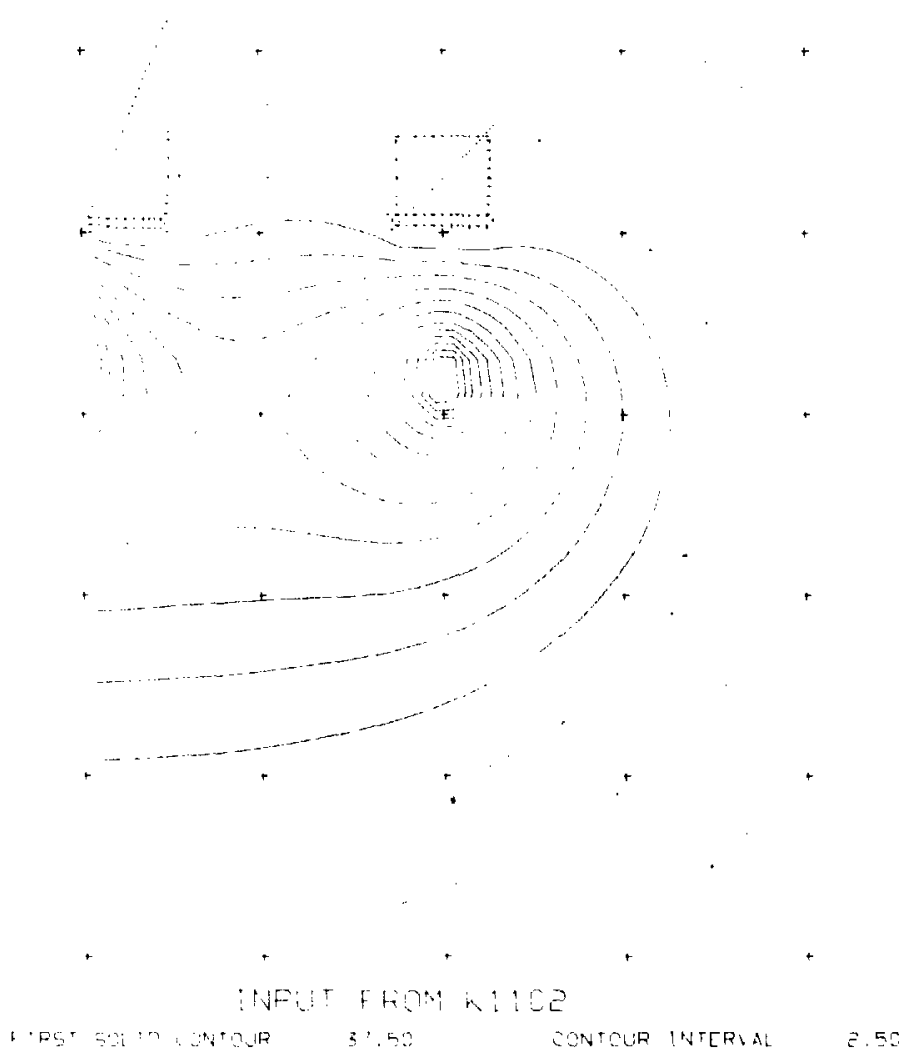

Figure 29. Temperature contours for SFT-C cross section at 7.50 years out of core; spent fuel was emplaced at 2.46 years out of core. 
Most of the action occurs during the first $11 / 2$ years of the test (up to 4.0 years out of core). After this time the $37.5^{\circ} \mathrm{C}$ contour (the first solid contour), for example, remains at about the same location near the drift while it progresses outwasd 2-4 $\mathrm{m}$ below and to the outside of the drifts. Temperature increases slightly outside this zone and decreases inside this zone due to continuing decay of the spent fuel and electrical simulators.

Similar temperature profiles have been developed for the first $1.5-\mathrm{m} \times$ 1.5-m region of the midplane of the unit cell used in the TRUMP calculations. Figures 30 through 40 are plan views showing contours in this region with tick marks, for scale, at $0.5-\mathrm{m}$ intervals. The contour interval is $2.5^{\circ} \mathrm{C}$ and the first solid contour is at $60^{\circ} \mathrm{C}$. Temperature contours within the first $1 / 6 \mathrm{~m}$ are inaccurate due to sparseness of data here caused by the presence of the thermal source.

Once again we see that most of the action takes place during the first $11 / 2$ years of the test and that substantial cooling occurs in the very near field due to decay of power sources. There are two intertiting features to observe in these contours. First, divergence of the contours near the top of the contour plot indicates interactions between the canisters. Second, the contours begin to parallel the right-hand boundary of the plot (which is not the mesh boundary). This indicates that the problem is becoming onedimensional, in this plane, roughly $1.5 \mathrm{~m}$ from the thermal sources. This observation is solid support of performing two-dimensional calculations in the plane perpendicular to the axis of the three-drift SFT-C complex, as was done for nearly all aspects of the present study. One must remember the limitations of two-dimensional modeling in regions near the ends of the SFT-C complex.

\section{SUMMARY}

Thermal analyses have been presented here that supported the design, construction, and operation of the Spent Fuel Test--Climax; a test of safe and reliable storage and retrieval of spent nuclear reactor fuel. As-huilt calculations utilized the best available properties and geometries associated with the SFT-C. These latest calculations will be used in evaluating thermal transport measurements at the test site. "They will in this way be applied to validating the ability of the models and codes used to predist heat transfer associated with this complex geometry. 


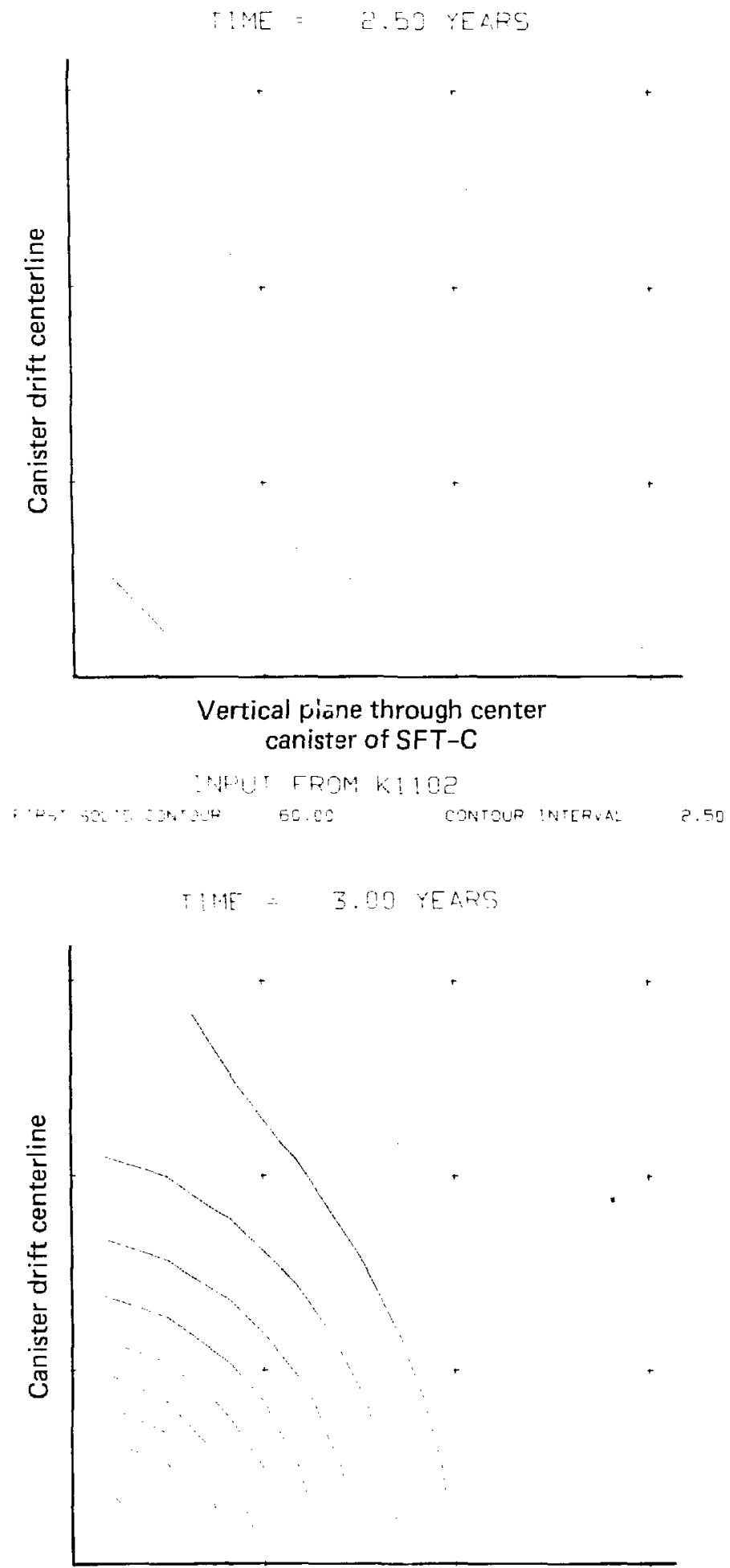

Figure 30. Temperature contours in plan view at 2.50 years out of core for quarter unit cell of SFT-C; spent fuel was emplaced at 2.46 years out of core.

Figure 31. Temperature conours in plan view at 3.00 years out of core for quarter unit cell of SFT-C; spent fuel was emplaced at 2.46 years out of core.

Vertical plane through center canister of SFT-C

UPFit FROM h: :

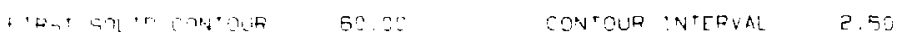


Figure 32. Temperature contours in plan view at 3.50 years out of core for quarter unit cell of SFT-C; spent fuel was emplaced 2.46 years out of core.

Figure 33. Temperature contours in plan view at 4.00 years out of core for quarter unit cell of SFT-C; spent fuel was emplaced at 2.46 years out of core.

2. 4 if lit

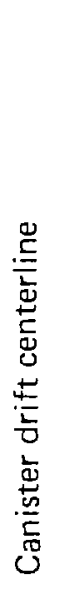

Vertical plane through center canister of SFT-C

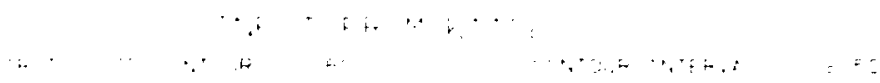

Vertical plane through center canister of SFT-C 


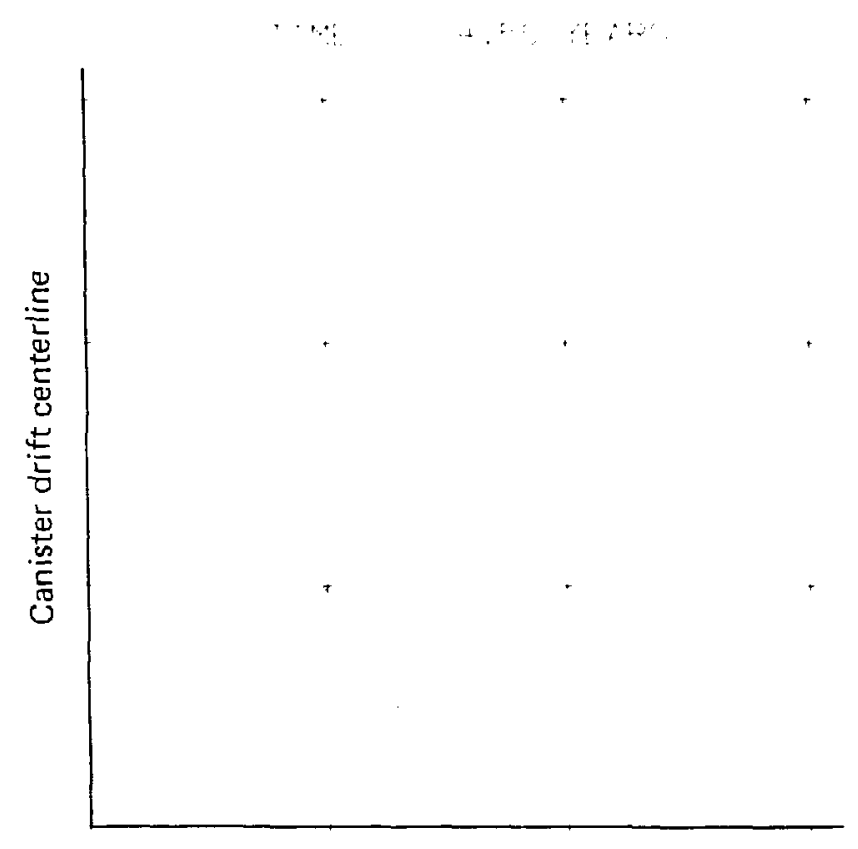

Vertical plane through center canister of SFT-C

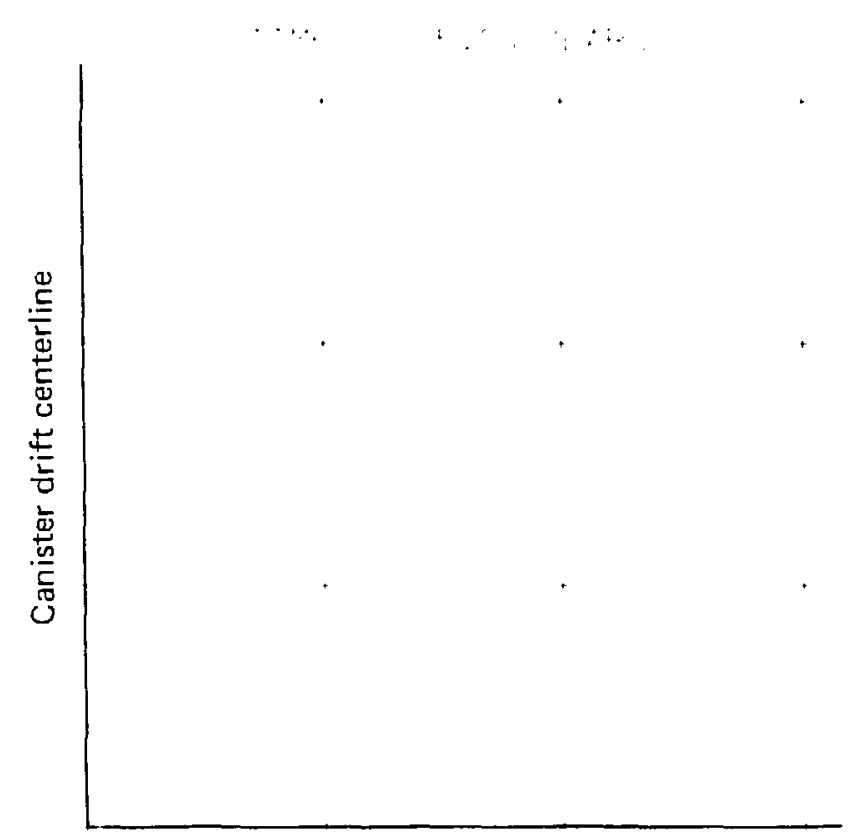

Vertical plane through center canister of SFT-C
Figure 34. Temperature contours in plan view at 4.50 years out of core for quarter unit cell of SET-C; spent fuel was emplaced at 2.46 years out of core.
Figure 35. Temperature contours in plan view at 5.00 years out of core for quater unit cell of SFT-C; spent fuel was emplaced at 2.46 years out of core. 
Figure 36. Temperature contours in plan view at 5.50 years out of core for quarter unit cell of SFT-C; spent fuel was emplaced at 2.46 years out of core.

Figure 37. Temperature contours in plan view at 6.00 years out of core for quarter unit cell of SFT-C; spent fue 1 was emplaced at 2.46 years out of core.

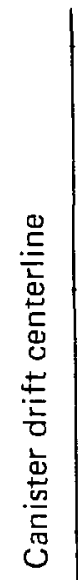

Vertical plane through center canister of SFT-C

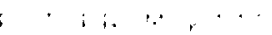

Vertical plane through center canister of SFT-C

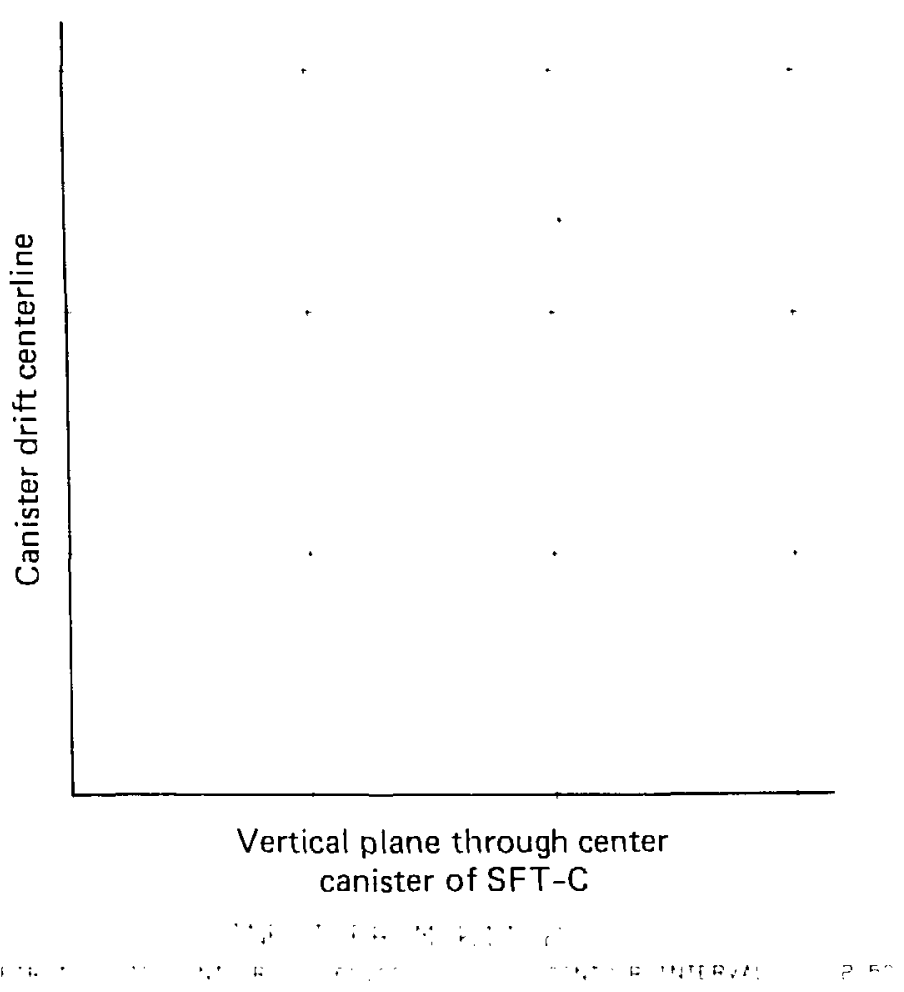




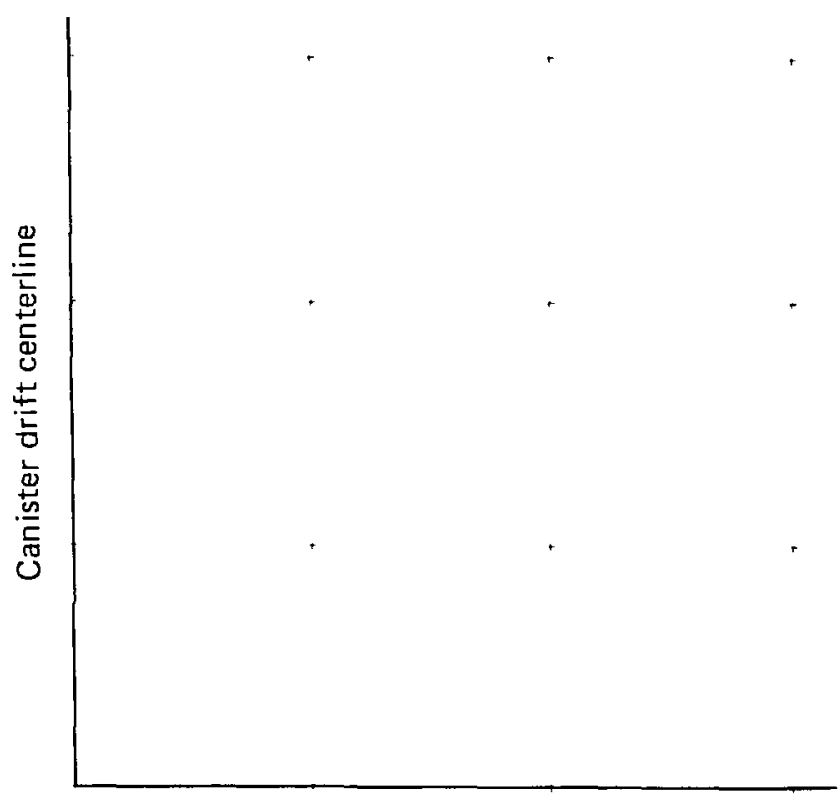

Vertical plane through center canister of SFT-C

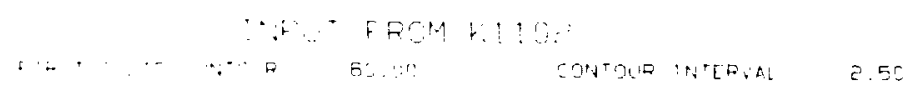

$$
\text { PH Y.0O IF APS }
$$

$$
\text { | }
$$

Vertical plane through center canister of SFT-C
Figure 38. Temperature contours in plan view at 6.50 years out of core for quarter unit cell of SFT-C; spent fuel was emplaced at 2.46 years out of core.
Figure 39. Temperature contours in plan view at 7.00 years out of core for quarter unit cell of SFT-C; spent fuel was emplaced at 2.46 years out of core. 


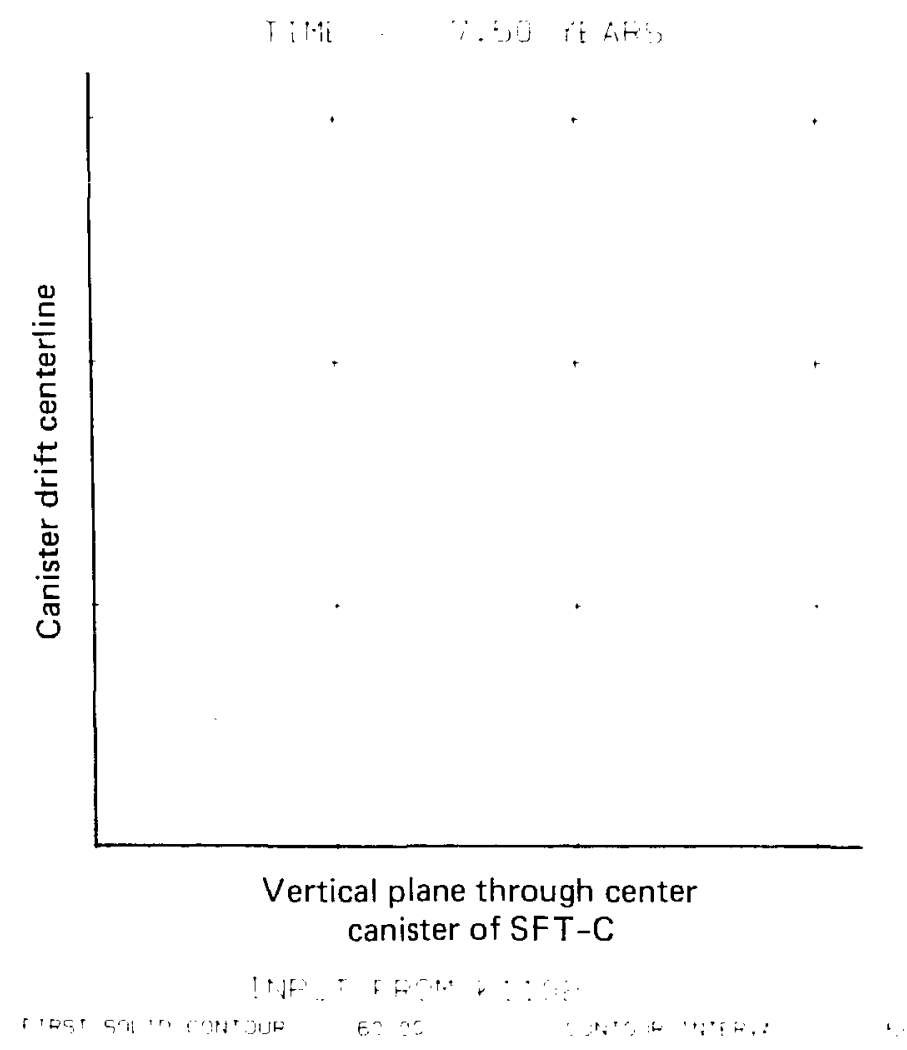

Figure 40. Temperature contours in plan view at 7.50 years out of core for quarter unit cell of SFT-C; spent fuel was emplaced at 2.46 years out of core.

Several points can be made regarding thermal analyses in general and as they apply to the Spent Fuel Test--climax. The general comments include:

1. Analytical techniques, properly applied, provide adequate results for conceptual design of test or prototype facilities. Even nearfield effects can be treated providing that heat sources are properly modeled as line segment sources rather than "smeared" planar sources. In general, analytical solutions are conservative in that heat loss due to ventilation and improved heat distribution due to convection and/or radiation are not treated.

2. Two-dimensional numerical models are adequate for all but very-nearfield studies of thermal transport, even for complex geometries.

3. Three-dimensional modeling is necessary only for very-near-field studies of details. We applied these models to calculate temperatures of shield plugs, canister wall, liner, rails, and similar construction features. 
4. Inclusion of either convective or radiative heat transfer mechanisms has a pronounced effect on the thermal regime in and around mined openings. Openings treated as insulators introduce large floor-to-roof gradients whereas properly treating convection and radiation results in openings that are nearly isothermal.

5. Ventilation should be included in thermal analyses if it is present in the actual facility. Ventilation can account for removal of a major proportion of the heat generated. We describe here a partial flow model that successfully models ventilation effects.

6. Proper establishment of external boundary conditions and size of mesh is easily checked by performing test calculations using both fixed temperature boundaries and adiabatic boundaries. If differences in calculated temperatures are within acceptable ranges, mesh size is adequate and external boundary conditions are unimportant for the times considered.

Comments specific to the SFT-C include:

1. Fuel-pin-cladding temperatures are not expected to exceed about $240^{\circ} \mathrm{C}$ with helium backfill gas present, or about $320^{\circ} \mathrm{C}$ should the helium be vented.

2. At the as-built ventilation rate of $2.65 \mathrm{~m}^{3} / \mathrm{s}$ to the $S F T-C$, air temperatures should permit moderate work activities to be carried out in reasonable comfort. Temperatures in the canister pits will be high (slightly over $60^{\circ} \mathrm{C}$ early in the test) but will not present a significant hazard to personnel installing instruments in this area.

3. Maximum temperatures in the very-near-field environment will be reached during the first 6 months of testing. Peak canister, liner, and emplacement-hole wall temperatures of about $140^{\circ} \mathrm{C}, 105^{\circ} \mathrm{C}$, and $80^{\circ} \mathrm{C}$, respectively, are anticipated. Peak temperatures at locations in the rock $0.50 \mathrm{~m}$ and $0.66 \mathrm{~m}$ from the canister centerline are about $70^{\circ} \mathrm{C}$ and $65^{\circ} \mathrm{C}$, respectively.

4. Temperature contours in the midplane of the thermal sources indicate approximately one-dimensional flow at about 1.5-2 $\mathrm{m}$ from the drift axis. This confirms the adequacy of two-dimensional modeling perpendicular to the drift axes. 


\section{ACKNOWLEDGMENTS}

The authors appreciate the careful reviews and constructive comments by L. B. Ballou, A. B. Miller, F. A. Morrison, L. D. Ramspott, L. D. Thorson, and O. R. Walton. Special acknowledgment is extended to L. B. Ballou, who provided the impetus for these calculations, and L. D. Thorson, who took part in technical discussions that led to implementation of several concepts and techniques presented here.

The assistance of Denice Verrett and Joanne Clark in preparing this manuscript is gratefully acknowledged. 
1. L. D. Ramspott, L. B. Ballou, R. C. Carlson, D. N. Montan, T. R. Butkovich, J. E. Duncan, w. C. Patrick, D. G. Wilder, W. G. Brough, M. C. Mayr, Technical Concept for a Test of Geologic Storage of Spent Reactor Fuel in the Climax Granite, Nevada Test Site, Lawrence Livermore National Laboratory, Livermore, CA, UCRL-52796 (1979).

2. D. N. Montan, Thermal Analysis for a Spent Reactor Fuel storage Test in Granite, Lawrence Livermore National Laboratory, Livermore, CA, UCRL-83995 (1980); also published in Proceedings of the International Symposium on the Scientific Basis for Nuclear Waste Management, (Plenum Press, New York, 1981), Vol. 3 .

3. W. C. Patrick, D. N. Montan, L. B. Ballou, Near-Field Heat Transfer at the Spent Fuel Test-Climax: A Comparison of Measurements and Calculations, Lawrence Livermore National Laboratory, Livermore, CA, UCRL-86043 (1981).

4. Final Environmental Impact Statement Nevada Test Site, Nye County, Nevada, 1977. Energy Research and Development Administration, Washington, DC, ERDA-1551.

5. F. Maldonado, summary of the Geology and Physical Properties of the Climax Stock, Nevada Test Site, U.S. Geological Survey, Denver, Co, Open-File Report 77-356 (1977).

6. L. Obert, Shot Hard Hat, Static Stress Determinations, Department of Defense, Washington, DC (1963).

7. F. H. Wright, Shot Pile Driver, In Situ Rock Stress, Department of Energy, Washington, DC (1967).

8. D. P. Rrynine and w. R. Judd, Principles of Eng ineering Geology and Geotechnics (McGraw-Hill Book Co., New York, 1957).

9. K. Szechy, The Art of Tunnelling (Akademiai Kiado, Budapest, 1966).

10. F. E. Heuze, W. C. Patrick, R. V. De la Cruz, C. F. Voss, In Situ Geomechanics, Climax Granite, Nevada Test Site, Lawrence Livermore National Laboratory, Livermore, CA, UCRL-53076 (1981).

11. L. D. Ramspott, Climax Granite Test Results, Lawrence Livermore National Laboratory, Livermore, CA, UCID-18502 (1980).

12. D. G. Wilder and W. C. Patrick, Geotechnical Status Report for Test Storage of Spent Reactor Fuel in Climax Granite, NTS, Lawrence Livermore National Laboratory, Livermore, CA, UCRL-85096 (1980). 
13. F. Holzer and L. D. Ramspott, Eds., Proceedings of a Workshop on Thermomechanical Modeling for a Hardrock Waste Repository, Lawrence Livermore National Laboratory, Livermore, CA, UCAR-10043 (1979).

14. A. L. Edwards, TRUMP, A Computer Program for Transient and steady state Temperature Distribution in Multidimensional Systems, Lawrence Livermore National Laboratory, Livermore, CA, UCRL-14754 Rev. 3 (1972).

15. L. D. Blackburn, D. G. Farwick, S. R. Fields, L. A. James, R. A. Moen, Maximum Allowable Temperature for storage of Spent Nuclear Reactor Fuel, Hanford Engineering Development Laboratory, Richland, WA, Rept. HEDL-TME 78-37 (May 1978).

16. R. K. Kibbe and A. L. Boch, Technical Support for GEIS: Radioactive Waste Is lation in Geologic Formations, Vol. 1, Office of Waste Isolation, Oak Ridge, TN, Y/OWI/TM-36/1 (April 1978).

17. R. C. Carlson, W. C. Patrick, D. G. Wilder, W. G. Brough, D. N. Montan, P. E. Harben, L. B. Ballou, H. C. Heard, SFT-C Technical Measurements Interim Report FY1980, Lawrence Livermore National Laboratory, Livermore, CA, UCRL-53064 (1980).

18. W. C. Patrick and M. C. Mayr, Excavation and Drilling Activities Associated with a spent Fuel Test Facility in Granitic Rock, Lawrence Livermore National Laboratory, Livermore, CA, UCRL-53277 (in preparation).

19. G. A. Izet, Granite Exploration Hole, Area 15, Nevada Test Site Nye

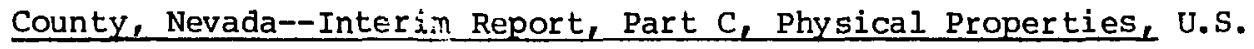
Geological Survey, Denvec, CO, Rept. TEM-836-C (1960).

20. R. Lingle and H. Pratt, Laboratory Measured Material Properties of Granodiorite, Climax Stock, Nevada Test Site, Terra Tek, Inc., Salt Lake City, Utah, Rept. TR 78-47 (August 1978).

21. W. B. Durham and A. E. ל:bey, "The Effect of Pressure and Temperature on the Thermal Properties of o Salt and a Quartz Monzonite," Proceedings of the 22nd U.S. Symposium on Rock Mechanics, Cambridge, MA (1981).

22. D. N. Montan ard W. E. Bradkin, Granite Heater Test \#l, Lawrence Livermore National Laboratory, Livermore, CA, UCRL-in preparation.

23. F. Schmittroth, G. J. Neely, J. C. Krogness, A Comparison of Measured and Calculated Decay Heat for Spent Fuel Near 2.5 Years Cooling Time, Hanford Eng ineering Development Laboratory, Richland, WA, HEDL-TC-1759 (1980) (Preliminary--Controlled Distribution). 